\title{
Myceliophthora thermophila Xyr1 is predominantly involved in xylan degradation and xylose catabolism
}

\author{
Ana Carolina dos Santos Gomes ${ }^{1 \dagger}$, Daniel Falkoski ${ }^{1,2 \dagger}$, Evy Battaglia ${ }^{1 \dagger}$, Mao Peng ${ }^{1}$, Maira Nicolau de Almeida ${ }^{1,3,4}$,
} Nancy Coconi Linares ${ }^{1}$, Jean-Paul Meijnen ${ }^{3,5}$, Jaap Visser ${ }^{1}$ and Ronald P. de Vries ${ }^{1 *}$ (D)

\begin{abstract}
Background: Myceliophthora thermophila is a thermophilic ascomycete fungus that is used as a producer of enzyme cocktails used in plant biomass saccharification. Further development of this species as an industrial enzyme factory requires a detailed understanding of its regulatory systems driving the production of plant biomass-degrading enzymes. In this study, we analyzed the function of MtXIr1, an ortholog of the (hemi-)cellulolytic regulator XInR first identified in another industrially relevant fungus, Aspergillus niger.
\end{abstract}

Results: The Mtx/r1 gene was deleted and the resulting strain was compared to the wild type using growth profiling and transcriptomics. The deletion strain was unable to grow on xylan and D-xylose, but showed only a small growth reduction on L-arabinose, and grew similar to the wild type on Avicel and cellulose. These results were supported by the transcriptome analyses which revealed reduction of genes encoding xylan-degrading enzymes, enzymes of the pentose catabolic pathway and putative pentose transporters. In contrast, no or minimal effects were observed for the expression of cellulolytic genes.

Conclusions: Myceliophthora thermophila MtXIr1 controls the expression of xylanolytic genes and genes involved in pentose transport and catabolism, but has no significant effects on the production of cellulases. It therefore resembles more the role of its ortholog in Neurospora crassa, rather than the broader role described for this regulator in $A$. niger and Trichoderma reesei. By revealing the range of genes controlled by MtXIr1, our results provide the basic knowledge for targeted strain improvement by overproducing or constitutively activating this regulator, to further improve the biotechnological value of $M$. thermophila.

Keywords: Myceliophthora thermophila, Xylanolytic regulator, Pentose catabolism, Xylan degradation, Cellulose degradation

\section{Background}

Plant biomass feedstocks are abundant and cheap waste materials which are increasingly used by different biobased industries to produce a range of products. Bioethanol and biodiesel are examples of such second-generation

\footnotetext{
*Correspondence: r.devries@westerdijkinstitute.nl

${ }^{\dagger}$ Ana Carolina dos Santos Gomes, Daniel Falkoski and Evy Battaglia contributed equally to this paper

${ }^{1}$ Fungal Physiology, Westerdijk Fungal Biodiversity Institute \& Fungal Molecular Physiology, Utrecht University, Uppsalalaan 8, 3584 CT Utrecht, The Netherlands

Full list of author information is available at the end of the article
}

biorefinery products which can be produced from lignocellulosic-rich biomass feedstocks [1]. These feedstocks include agricultural residues (e.g., by-products of cereal crops and sugarcane bagasse), forestry waste (e.g., wood chips and sawdust) and perennial grasses (e.g., miscanthus and switchgrass) [2, 3]. Lignocellulose is a heterogeneous and recalcitrant substrate that consists mainly of polysaccharides and lignin [4]. Its degradation requires costly processes, e.g., a thermochemical pre-treatment followed by enzymatic hydrolysis, to degrade those polysaccharides into fermentable sugars for the production of bioethanol or biochemicals [5]. Currently, there is still 
a need to improve available bacterial and fungal enzyme preparations [6]. To reduce the costs of the hydrolysis process, enzymes and enzyme mixtures are needed that are able to more efficiently and more completely solubilize the lignocellulosic material resulting in higher yields of fermentable sugars, above the $60 \%$ that is currently often reached.

The application of thermostable enzymes to saccharify lignocellulosic feedstocks is therefore gaining wide industrial interest [7]. Thermostable enzymes have several advantages over mesophilic enzymes, such as higher thermal stability enabling longer hydrolysis times if needed and higher specific activity at higher temperatures thus reducing the enzyme dosage needed [8]. The use of higher temperatures during saccharification (e.g., $50-60{ }^{\circ} \mathrm{C}$ ) will result in better substrate solubility and lower viscosity, higher mass transfer rates and a lowered risk of contamination [9]. Therefore, applying thermostable enzymes in lignocellulose saccharification may lead to a decrease in enzyme dosage, faster conversion rates and higher sugar yields, thus reducing the overall production costs.

Myceliophthora thermophila is such a thermophilic ascomycete fungus, which is soilborne and also occurs in self-heated compost [10]. M. thermophila is known to produce a complete set of cellulolytic enzymes that act synergistically when grown on cellulose $[11,12]$. A large set of lignocellulosic enzymes from $M$. thermophila has previously been biochemically characterized (reviewed in [13]). All enzymes have optimal activity at temperatures between 40 and $85{ }^{\circ} \mathrm{C}$, and many of them display high thermostability [13-17]. Besides these characterized enzymes, the genome of $M$. thermophila contains many more genes encoding (putative) carbohydrate-active enzymes involved in oxidative and hydrolytic (hemi-) cellulose degradation. Those may also have thermophilic properties of interest for industrial applications [10, 13, 18]. This powerful potential for lignocellulose conversion has been shown when the fungus was grown on various untreated agricultural substrates $[10,19-21]$ and on pretreated plant biomass $[19,22]$. For this reason, the industrial $M$. thermophila strain $\mathrm{C} 1$ was developed into an enzyme production platform, optimized for commercialscale production of xylanolytic and cellulolytic enzymes to release both C5 and C6 sugars efficiently [23].

The production of lignocellulosic enzymes is mainly regulated at the transcriptional level in ascomycete fungi. Three transcription factors play a dominant, but not always the same role in the breakdown of cellulose and hemicellulose: $\mathrm{Clr} 1$ (ClrA) and Clr2 (ClrB) [24] and $\mathrm{X} \ln R(\mathrm{Xyr} 1 / \mathrm{Xlr} 1)[25,26]$. In this paper we focus on the xylanolytic activator XlnR (Xyr1/Xlr1), which thus far is the most extensively studied transcription factor involved in lignocellulose degradation in ascomycete filamentous fungi. XlnR/Xyr1 is involved in the regulation of both cellulolytic and hemicellulolytic genes in A. niger, Aspergillus oryzae and T. reesei [25, 27-29]. However, previous studies showed differences in the function of XlnR (Xyr1/ $\mathrm{Xlr} 1$ ) in different filamentous fungi such as $N$. crassa and Magnaporthe grisea where this factor is only required for hemicellulose degradation $[25,30]$.

Overexpression of the $x \ln R$ homolog in the $M$. thermophila ATCC42464 strain (Mtxyr1) has been found to result in an increase in xylanase production, but not in cellulase production during growth on media containing an agricultural waste substrate (corncobs) or D-glucose [31]. Therefore, we decided to investigate the xylanolytic system and its regulation in this industrially relevant fungus in more detail to create the knowledge base required for a dedicated strain improvement program. While we have used a different strain than ATCC42464 and differences between strains cannot be excluded, both strains have been demonstrated to be closely related using phylogenetic means (de Vries et al. unpublished results).

\section{Results}

Deletion of Mtxyr 1 affects growth on D-xylose and different xylans, and uptake of D-xylose

The complete ORF of the Mtxyr1 gene was deleted in M. thermophila $\mathrm{C} 1$ by targeted gene replacement via homologous recombination and verified by PCR analysis in three independent transformants (see Methods and Additional file 1: Fig. S1) with identical phenotypes. Two transformants were complemented with the wildtype gene, restoring the wild-type phenotype (Additional file 1: Fig. S2). Based on this, one of the transformants ( $\Delta x y r 1.1 C$; further referred to as $\Delta M t x y r 1)$ was used for further analyses.

$\Delta M$ txyrl showed hardly any growth on solid media plates with D-xylose and birchwood xylan, reduced growth on wheat arabinoxylan compared to the wild type, while growth was only slightly reduced on L-arabinose (Fig. 1). No effect on growth of $\Delta M t x y r 1$ was observed on D-glucose, cellobiose, Avicel and cellulose (Fig. 1).

To determine whether deletion of Mtxyr 1 has an effect on uptake of D-xylose and L-arabinose, the wild-type and $\Delta M t x y r 1$ were pre-grown in minimal medium with $\mathrm{D}$-fructose for $48 \mathrm{~h}$ in liquid shake flask cultures and aliquots of mycelium were then transferred to shake flask cultures with L-arabinose or D-xylose (see Materials and Methods). D-xylose and L-arabinose concentrations were measured in the extracellular medium over time (Fig. 2). During cultivation of the wild type in minimal medium with D-xylose or L-arabinose alone, each sugar 


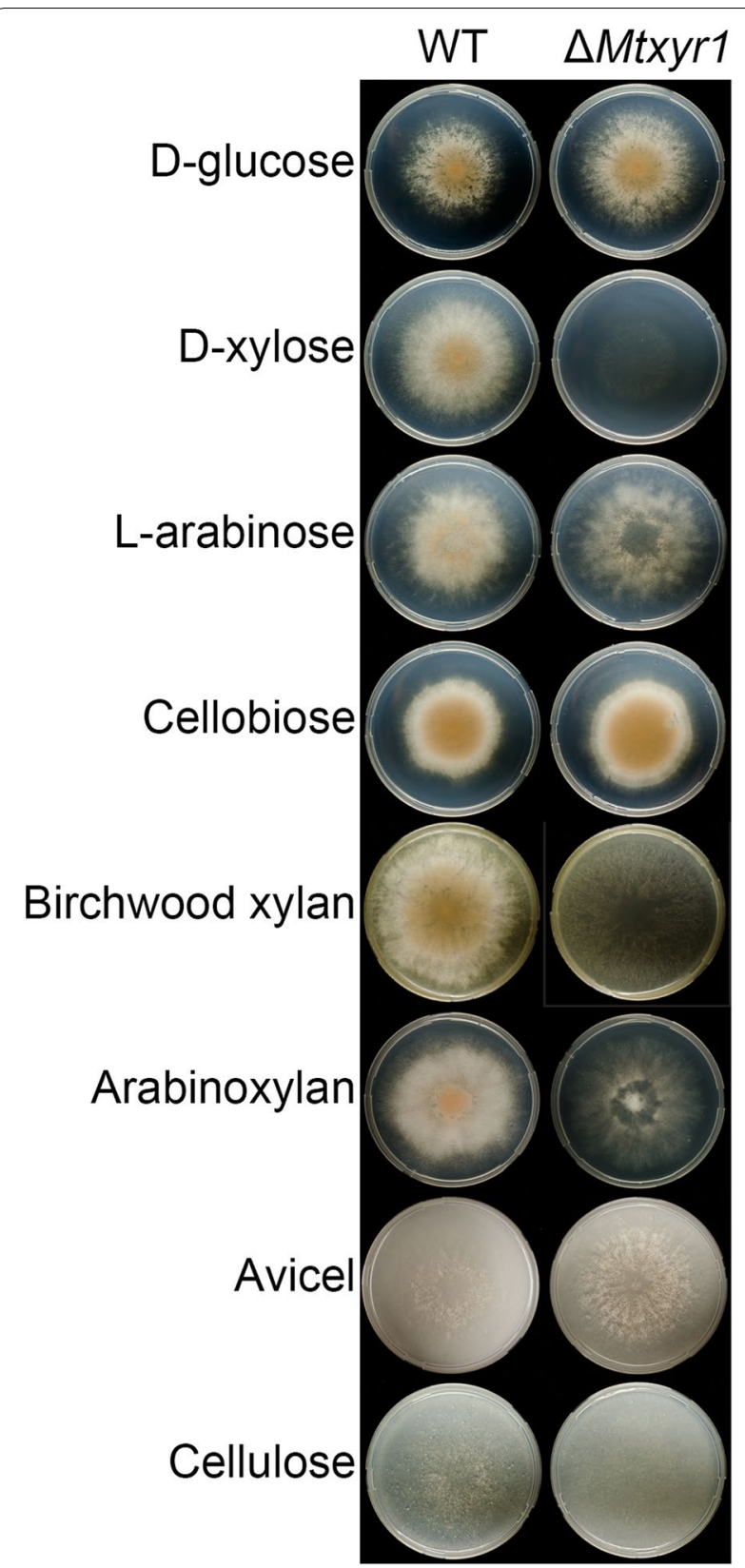

Fig. 1 Growth phenotype of the M. thermophila wild type and $\Delta x y r 1$ on agar plates. The wild-type strain and the Mtxyr 1 deletion mutant $\left(\Delta M\right.$ txyr 1 ) were grown for 5 days at $37^{\circ} \mathrm{C}$ on solid minimal medium containing different mono- oligo- and polymeric carbon sources

concentration decreased slowly during the first $12 \mathrm{~h}$ of growth (Fig. 2), but more rapidly during the next $12 \mathrm{~h}$. $\mathrm{D}$-xylose and L-arabinose were depleted after $24 \mathrm{~h}$ and $33 \mathrm{~h}$, respectively. The $\mathrm{D}$-xylose concentration in the extracellular medium of $\Delta M t x y r 1$ remained at a similar level during $48 \mathrm{~h}$ of growth (Fig. 2), while L-arabinose gradually decreased over time, yet slower than in the wild type, to be completely depleted after $48 \mathrm{~h}$.
The activity of endo-xylanases, $\beta$-xylosidases and cellobiohydrolases is reduced in the $\Delta M t x y r 1$ strain on D-xylose, L-arabinose and/or different xylans Deletion of Mtxyr1 negatively affected $\beta$-xylosidase (BXL) and endo-xylanase (XLN) activities after $24 \mathrm{~h}$ of growth on D-xylose, L-arabinose, wheat arabinoxylan and birchwood xylan (Fig. 3). Interestingly, BXL and XLN activities were higher on $\mathrm{L}$-arabinose than on $\mathrm{D}$-xylose in the wild type after $24 \mathrm{~h}$ of growth. $\alpha$-Arabinofuranosidase (ABF) activity was higher in the wild type on L-arabinose and wheat arabinoxylan compared to the other substrates. However, deletion of Mtxyr1 resulted in only a $40 \%$ reduction of $\mathrm{ABF}$ activity on $\mathrm{L}$-arabinose, while there was an increase in the ABF activity of the mutant of $50 \%$ on wheat arabinoxylan.

We observed no reduced activities of $\beta$-glucosidases (BGL) and endo-glucanases (EGL) in $\Delta M$ txyrl after $24 \mathrm{~h}$ of growth on all substrates (Fig. 3). EGL activity was only detected in $24 \mathrm{~h}$ samples of both the wildtype and $\Delta M t x y r 1$ grown on L-arabinose and Avicel and in $\Delta M t x y r 1$ on wheat arabinoxylan. Deletion of Mtxyr 1 resulted in a strong reduction in cellobiohydrolase $(\mathrm{CBH})$ activity levels after the $24 \mathrm{~h}$ transfer on D-xylose and $\mathrm{L}$-arabinose, but $\mathrm{CBH}$ activity was not or only weakly affected on cellobiose and Avicel. The cellulolytic enzyme activities are higher in the deletion strain on Avicel (1.5to 2-fold for BGL and $\mathrm{CBH}$ ).

\section{MtXyr1 is mainly involved in regulation of expression of xylanolytic genes on both D-xylose and L-arabinose} RNA-seq was used to study the effect of the Mtxyr 1 deletion on transcript levels of genes encoding Carbohydrate Active enZymes (CAZymes). The wild-type and $\Delta M t x y r 1$ strains were pre-grown in CM medium containing $2 \%$ $\mathrm{D}$-fructose and aliquots of the mycelium were transferred for $2 \mathrm{~h}$ to minimal media containing $25 \mathrm{mM} \mathrm{D}$-glucose, $\mathrm{D}$-xylose or L-arabinose and for 2 and $8 \mathrm{~h}$ to minimal medium containing $1 \%$ wheat arabinoxylan. These time points were chosen to reflect the initial response $(2 \mathrm{~h})$ of the strains to the new conditions selected and how this response alters over time $(8 \mathrm{~h})$.

First, we studied the transcript levels of the CAZy genes that contain at least one predicted auxiliary activity (AA), carbohydrate esterase (CE), glycoside hydrolase $(\mathrm{GH})$ or polysaccharide lyase (PL) domain (Additional file 2). A selection was made of the CAZy families that are known or predicted to be involved in plant polysaccharide degradation in Aspergillus nidulans [32]. A cutoff fold change of the data from the mutant compared to the wild type of $>2.0$ and a $p$ value of $\leq 0.01$ was used to identify differentially expressed genes (Fig. 4 and Additional file 2). Only genes expressed above 5 RPKM in at least 
wild-type

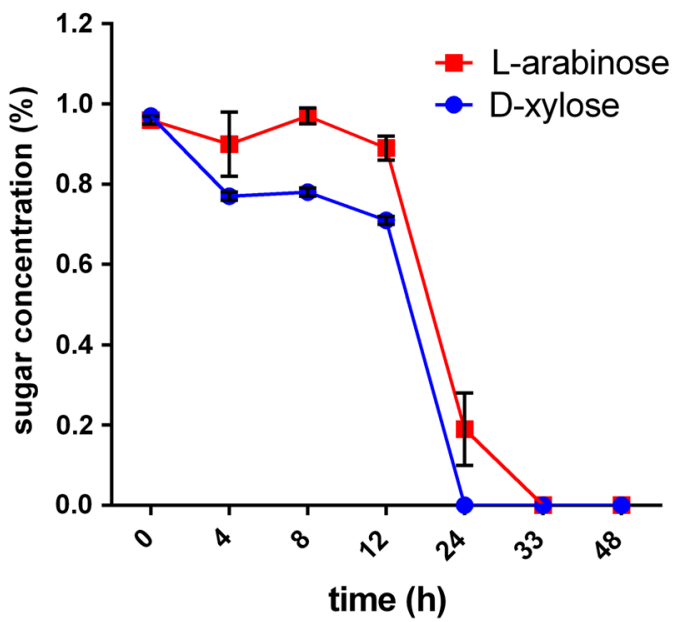

$\Delta M t x y r 1$

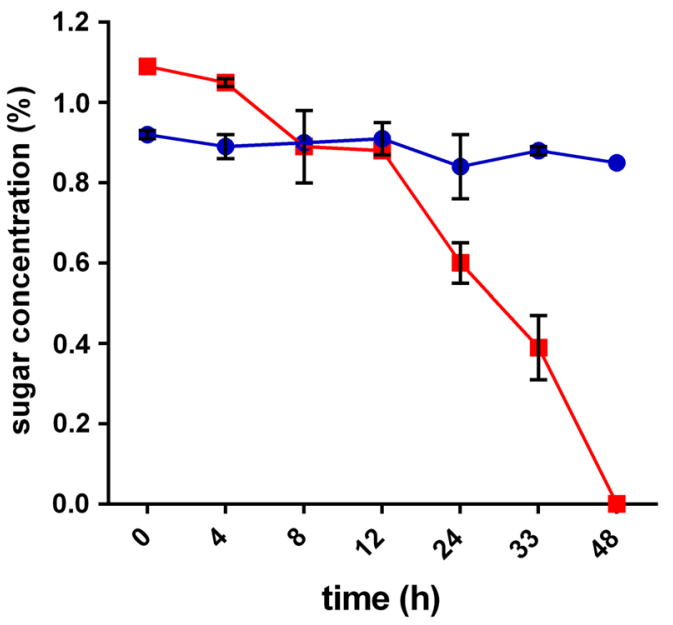

Fig. 2 Extracellular L-arabinose and D-xylose concentration during $48 \mathrm{~h}$ of growth of the wild-type and $\Delta M t x y r 1$ strain in liquid cultures. Extracellular L-arabinose (red line) and D-xylose (blue line) concentration measurements of the wild type and $\Delta M t x y r 1$ grown in $50 \mathrm{~mL}$ liquid shake flask cultures with L-arabinose or D-xylose

one sample were included in the expression profile analysis in the next paragraphs.

Transcript levels of 34 genes were induced on D-xylose compared to D-glucose in the wild type, while 15 of these genes were also induced on L-arabinose (Fig. 4). Most genes induced on both pentoses are known/predicted to be involved in xylan degradation. The 20 CAZy genes that are only induced on D-xylose are known/predicted to be involved in xylan, cellulose and starch degradation (the genes of group 1 and 6, see Fig. 4).

Transcript levels of the CAZy genes of group 1, 2 and 3 were all significantly decreased in $\Delta M t x y r 1$ (Fig. 4).

As expected, this group consists of genes encoding hydrolytic enzymes (GH10, GH11, GH43) involved in xylan degradation, but remarkably also contains a large number of LPMO's. The expression of 6 out of 24 LPMO genes was lower in $\Delta M$ txyr1 on D-xylose (Fig. 4, group 1). Two of these group 1 AA9 genes, encoding $M t$ LPMO9A and $M t L P M O 9 B$ from $M$. thermophila $\mathrm{C} 1$, were studied before and were shown to be active toward regenerated amorphous cellulose (RAC) and cellulose, whereas $M t$ LPMO9A was also active toward xylan associated with RAC, xyloglucan and mixed glucan [33].

Group 2 contains genes of which transcript levels were decreased in $\Delta M t x y r 1$ on both $\mathrm{D}$-xylose and L-arabinose (Fig. 4). Almost all genes encode main chain cleaving and accessory enzymes involved in xylan degradation, except for a predicted $\mathrm{GH} 2 \beta$-mannosidase and a predicted GH12 xyloglucan-specific endo-glucanase. Group 3 contains genes that had low RPKM values (between 5 and 30 ), but they were L-arabinose induced and transcript levels were significantly decreased in $\Delta M t x y r 1$ on L-arabinose. Most genes of this group are involved in xylan and pectin degradation, for example those encoding the $\alpha$-Larabinofuranosidases Abf3 and Abn4, and the feruloyl esterase FaeA1 [34, 35].

Genes that were not dependent on $M t \mathrm{Xyr} 1$ are presented in group 4, 5 and 6 (Fig. 4). Group 4 consists of a set of genes only induced on L-arabinose of which the transcript levels were not influenced by $M t \mathrm{Xyr} 1$. These genes mainly encode arabinan- and arabinoxylan-degrading enzymes. Group 5 includes three genes that encode a GH7 cellobiohydrolase (Cbh1a), a predicted GH13_3 $\alpha$-amylase and a predicted PL1_10 pectate lyase which show increased transcript levels on both D-xylose and $\mathrm{L}$-arabinose, but were not affected by deletion of Mtxyr1. Group 6 includes genes expressed in the presence of $\mathrm{D}$-xylose that are not MtXyr1 dependent. Almost all those genes are involved in starch and cellulose degradation. Only one of these genes, encoding the CE1 acetylxylan esterase Axe3, is active toward acetylated xylans [36]. Three starch-degrading genes (a predicted GH13 $\alpha$-amylase, a starch-binding GH15 glucoamylase and a GH13 $\alpha$-glucosidase) from this group were significantly up-regulated in $\Delta M t x y r 1$ on D-xylose, likely as a response to the inability to utilize $\mathrm{D}$-xylose.

In summary, transcript levels of none of the endo-glucanases or cellobiohydrolases belonging to the GH5, 6 and 7 families were affected by the deletion of Mtxyr 1 on $\mathrm{D}$-xylose or L-arabinose at the $2 \mathrm{~h}$ time point (Fig. 4). The transcript level of a predicted GH5_5 endo-glucanase did increase on D-xylose, but was unaffected in the absence 


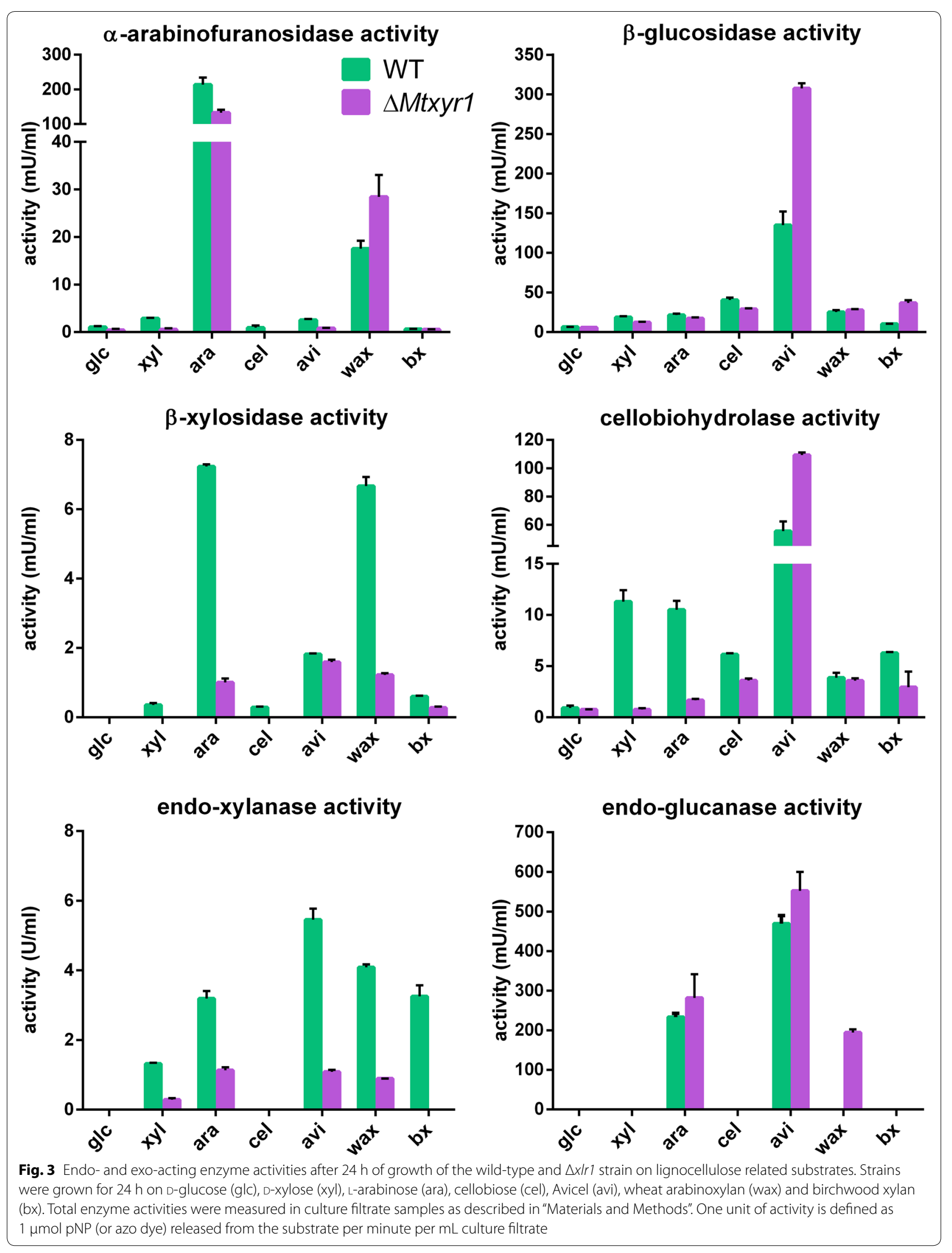




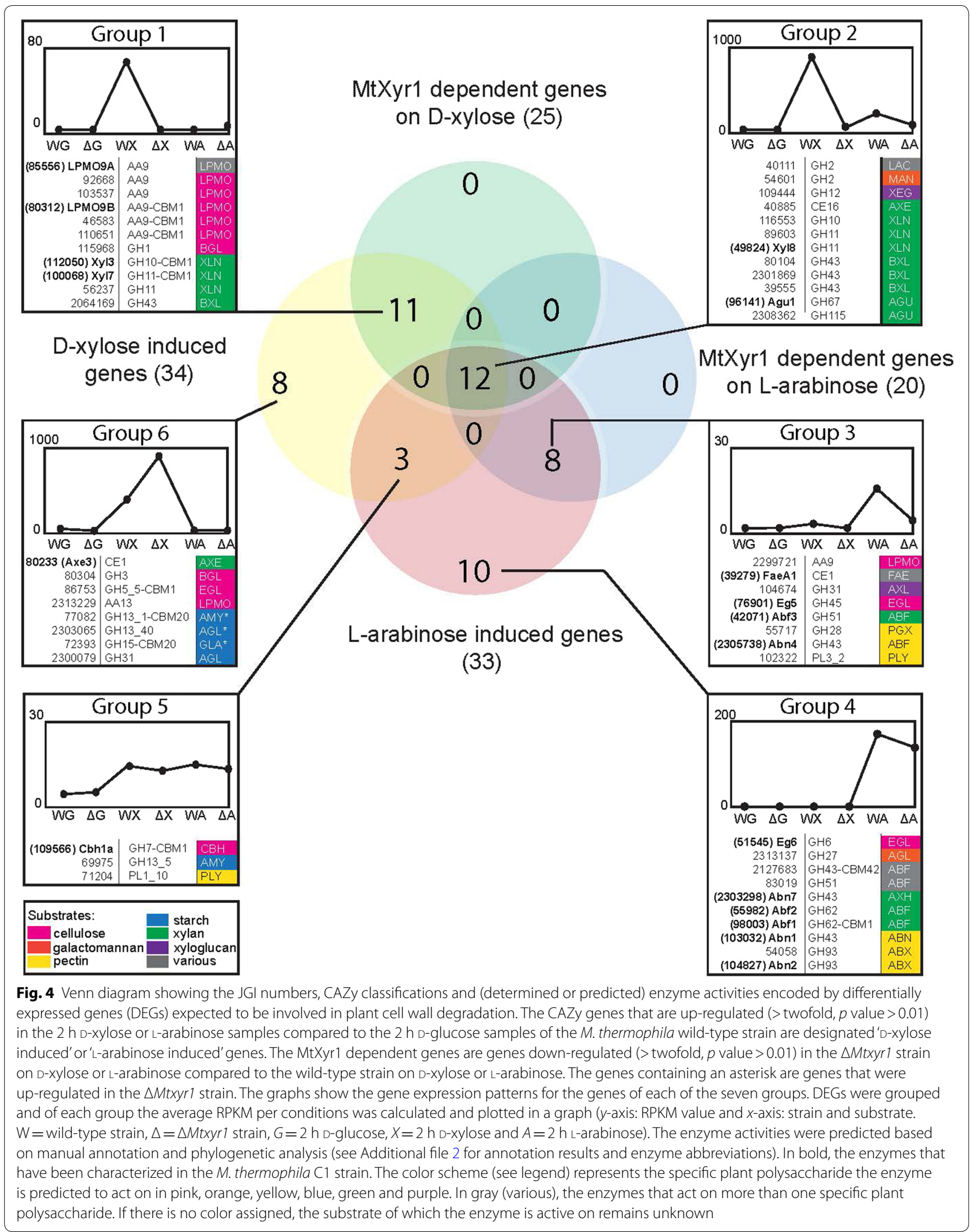


of Mtxyr1 (Fig. 4, group 6). There was only one GH45 endo-glucanase (Eg5) that was L-arabinose induced and down-regulated in $\Delta M t x y r 1$ on L-arabinose (Fig. 4, group 3).

\section{Not all xylanolytic genes remain down-regulated in $\Delta$ Mtxyr 1 during growth on wheat arabinoxylan}

To identify CAZy genes regulated by Xyr1 in $M$. thermophila on wheat arabinoxylan, we used RNA-seq to determine changes in mRNA levels in the wild type and $\Delta M t x y r 1$ at two time points, $2 \mathrm{~h}$ and $8 \mathrm{~h}$. CAZy genes were considered to be time-independently regulated by $M t \mathrm{Xyr}$, if at both time points the transcript levels were more than twofold decreased in $\Delta M t x y r 1$ compared to the wild type.
The expression of 24 CAZy genes was significantly lower in the $\Delta M t x y r 1$ strain at $2 \mathrm{~h}$ on wheat arabinoxylan (Fig. 5a). Many of these genes encode enzymes involved in the degradation of xylan, including seven known/ predicted GH10 and GH11 endo-xylanases and nine predicted xylanolytic accessory enzymes. The decrease in transcript levels of a set of LPMO genes that was observed at the $2 \mathrm{~h}$ time point on $\mathrm{D}$-xylose in $\Delta M$ txyr 1 (Fig. 4; group 1) was also observed on wheat arabinoxylan at the $2 \mathrm{~h}$ time point (Fig. $5 \mathrm{a}$ ), except for one predicted AA9 LMPO (JGI: 46583). Initially, deletion of Mtxyr 1 had a negative effect on transcript levels of three other CAZy genes involved in the degradation of cellulose (GH6 endo-glucanase EG6) and of xyloglucan (JGI: 109444; a predicted GH12 xyloglucan endo-glucanase) as

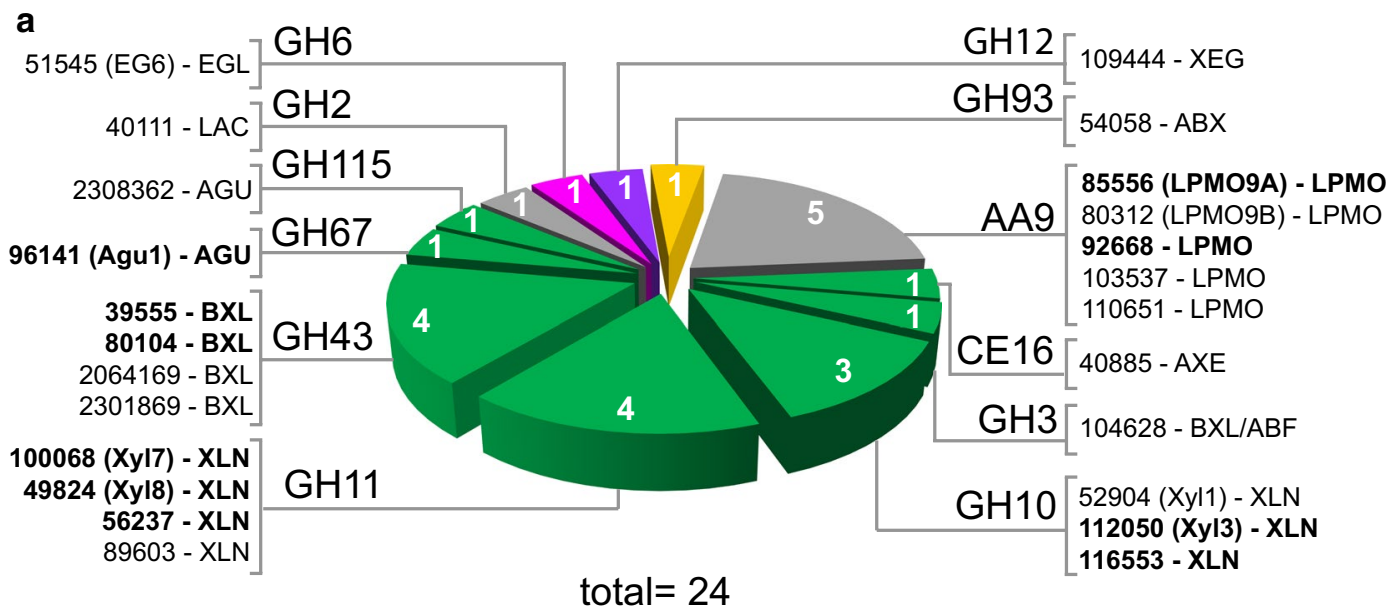

b

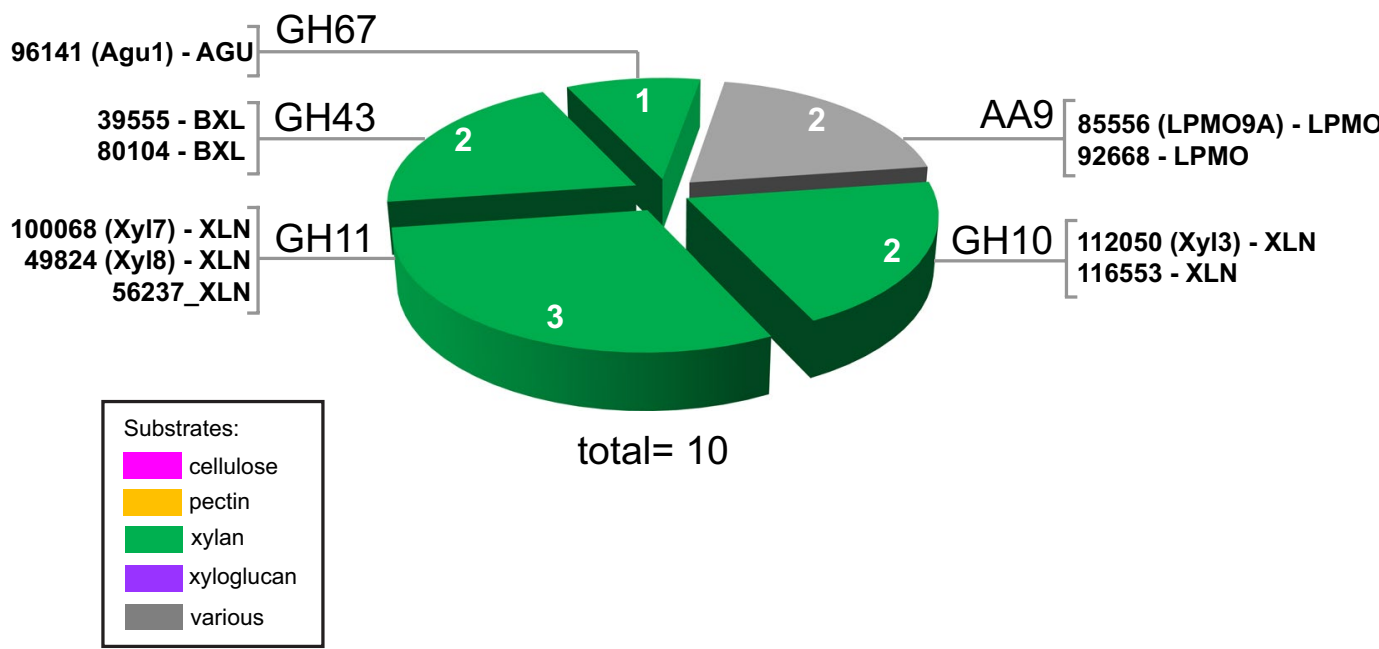

Fig. 5 The numbers of down-regulated genes per CAZy family in the $\triangle M$ txyr1 strain on wheat arabinoxylan compared to the wild-type strain. a Down-regulated (> twofold, $p$ value $>0.01$ ) CAZy genes at the $2 \mathrm{~h}$ time point and $\mathbf{b} 8 \mathrm{~h}$ time point in the $\triangle M$ txyr 1 strain. Only the GH, AA, CE or PL families predicted to be involved in plant cell wall degradation per gene are shown. For additional information (enzyme abbreviations and the presence of CBM modules, see Additional file 2). In gray (various/unknown), the enzymes that act on more than one specific plant polysaccharide or of which the substrate it acts on remains unknown 
well as in pectin degradation (JGI: 54058; a GH93 exoarabinanase). However, transcript levels did not remain low at the $8 \mathrm{~h}$ time point in the $\Delta M t x y r 1$ strain (Fig. $5 \mathrm{~b}$ ). Expression of only 10 of these 24 genes remained significantly lower in the $\Delta M$ txyrl strain at $8 \mathrm{~h}$. These CAZy genes encode mainly xylan-degrading enzymes including five known/predicted GH10 and GH11 endo-xylanases (Xyl3, Xyl7, Xyl8, JGI: 56237 and JGI: 116553), two predicted GH43 $\beta$-xylosidases (JGI: 39555 and JGI: 80104), one $\alpha$-glucuronidase (Agu1) and two LPMO's (MtLPMO9A and JGI: 92668).

Interestingly, transcript levels of many genes were significantly increased in $\Delta M t x y r 1$ compared to the wild type at both time points on wheat arabinoxylan (Fig. 6a). A total of 28 CAZy genes were up-regulated at $2 \mathrm{~h}$. Among these CAZy genes, there is a set of genes predicted to be involved in starch degradation (six genes encoding two predicted GH13_40 $\alpha$-glucosidases, a GH31 $\alpha$-glucosidase, a GH13_5 amylase and two GH15 glucoamylases), a set of genes involved in cellulose degradation (five genes including a GH6 and a GH7 cellobiohydrolase, a GH7 endoglucanase, an AA9 LPMO and an AA8/AA3 cellobiose dehydrogenase) and a set involved in galactomannan degradation (three genes including two GH2 $\beta$-mannosidases and a GH27 $\alpha$-galactosidase). The other 14 up-regulated CAZy genes in $\Delta M t x y r 1$ at $2 \mathrm{~h}$ were predicted to be mainly exo-acting enzymes acting on xyloglucan, pectin and various substrates.

At $8 \mathrm{~h}$, the number of up-regulated CAZy genes increased to 42 (Fig. 6b), including sets of CAZy genes predicted to be involved in degradation of xylan (eight genes) and pectin (13 genes). Among these genes are those encoding enzymes releasing arabinan oligomers and L-arabinose. Some of these, $a b n 1, a b n 2, a b f 1$ and $a b f 2$, were also up-regulated on L-arabinose, whereas transcript levels were unaffected by deletion of Mtxyr 1 (Fig. 4; group 4).

\section{Deletion of Mtxyr1 also affects the transcription levels of some sugar transporter-encoding genes}

The effect of deleting the Mtxyr1 gene on transcript levels of 45 putative transporter genes in the $M$. thermophila genome was also analyzed. When all conditions and both strains were compared, 35 differentially expressed genes were detected (Fig. 7). The comparison for the three monosaccharides used is depicted in Fig. 7. The transcript levels of five putative transporter genes were induced on $\mathrm{D}$-xylose and significantly decreased in $\Delta$ Mtxyr 1 after $2 \mathrm{~h}$ on D-xylose (Fig. 7 and Additional file 1: Fig S3). These include two genes of the second cluster (JGI: 108890 and 2302949) and three genes of the third cluster (JGI: 84164, 114107 and JGI: 96047) (Fig. 7). The latter gene is an ortholog of the A. nidulans D-xylose transporter (XtrD) that has been shown to be XlnR dependent in the presence of D-xylose in this fungus [37]. The two cluster 2 genes showed a highly similar transcription profile: both genes were induced on $\mathrm{D}$-xylose, down-regulated in $\Delta M t x y r 1$ on D-xylose and up-regulated in the deletion strain at both time points on wheat arabinoxylan. JGI: 108890 is an ortholog of the $A$. niger D-galacturonic acid transporter (GatA) [38], while JGI: 2302949 is an ortholog of the $\mathrm{D}$-xylose-induced transporter gene AN4148 (XtrE) of A. nidulans [37]. Transcript levels of JGI: 96047 were highly induced on D-xylose (400-fold compared to D-glucose), also induced on L-arabinose and wheat arabinoxylan (Additional file 1: Fig. S3), but down-regulated in the $\Delta M t x y r 1$ strain in all conditions. The transcript levels of the other two cluster 3 genes, JGI: 84164 and JGI: 114107, were lower in $\Delta M$ txyr1 on L-arabinose and D-xylose. JGI: 114107 is an ortholog of the $N$. crassa cellodextrin/xylodextrin transporter CDT-2 gene that has been shown to be regulated by XLR-1, CLR-1 and CLR-2 during growth of $N$. crassa on cellulose and xylan [30,39, 40]. JGI: 84164 is predicted to belong to the clade $\mathrm{H}$ of sugar transporters, including lactose permeases, cellodextrin transporters and members that are able to transport melezitose and turanose [41].

There were 11 putative transporter genes induced on $\mathrm{L}$-arabinose (Additional file 3 ). Transcript levels of the two genes belonging to cluster 4 (JGI: 95427: the $M$. thermophila L-arabinose transporter (MtLAT-1) and JGI: 2305795) were highly induced (a 60- and 96-fold change, respectively, compared to D-glucose) and remained unchanged in $\Delta M t x y r 1$ on L-arabinose. Transcript levels of five L-arabinose-induced transporter genes (JGI: 58642, JGI: 84164, JGI: 96047; the $A$. nidulans XtrD ortholog, JGI: 114107; the N. crassa CDT-2 ortholog and JGI: 2307233) decreased in the $\Delta M t x y r 1$ strain on $\mathrm{L}$-arabinose.

Cluster 2, 4 and 5 include sugar transporter genes of which transcript levels highly increased in $\Delta M t x y r 1$ at $8 \mathrm{~h}$ on wheat arabinoxylan (Additional file 1, Fig. S3) and for several genes at both $2 \mathrm{~h}$ and $8 \mathrm{~h}$. Clusters 6 and 7 contain lowly expressed genes and only minor changes in transcript levels occurred.

\section{Deletion of Mtxyr1 affects the transcription of genes involved in the pentose catabolic pathway (PCP) and pentose phosphate pathway (PPP)}

Deletion of Mtxyr1 significantly decreased the transcript levels of ten genes predicted to be involved in primary metabolism during growth of $M$. thermophila on D-xylose (Fig. 8, Additional files 1: Fig. S4 and 4). This included four genes predicted to encode the pentose 


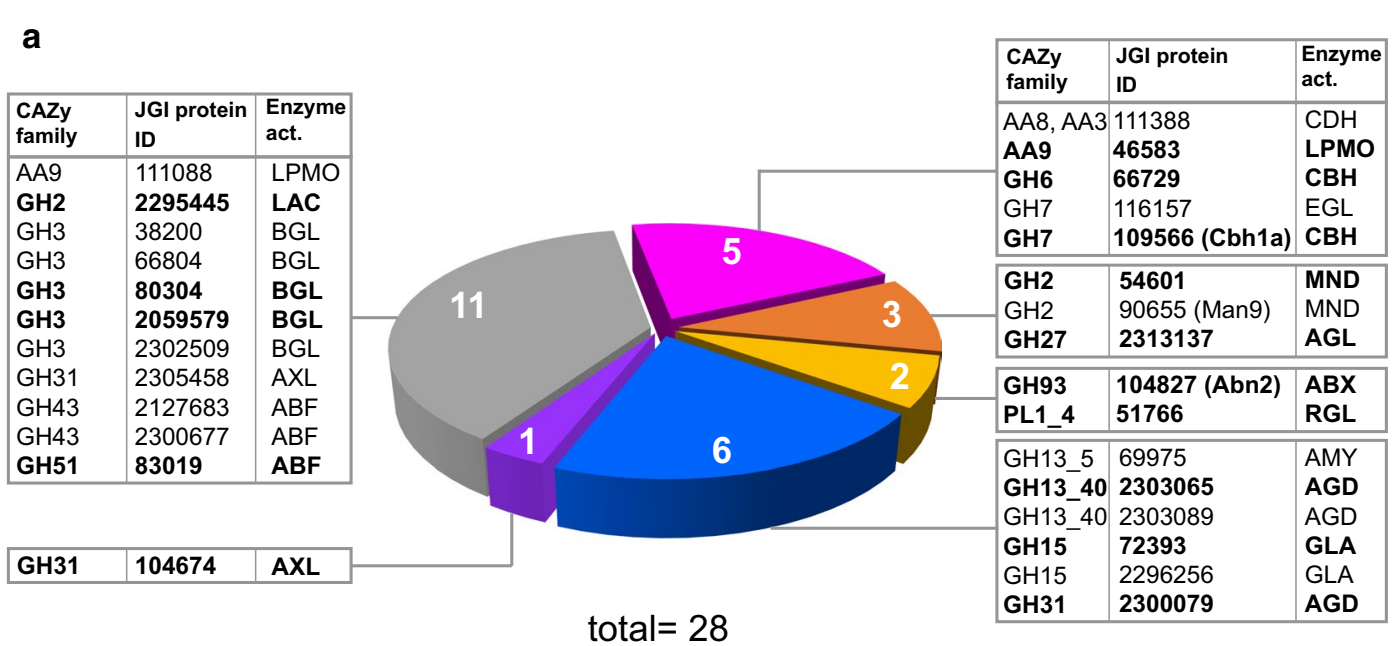

b

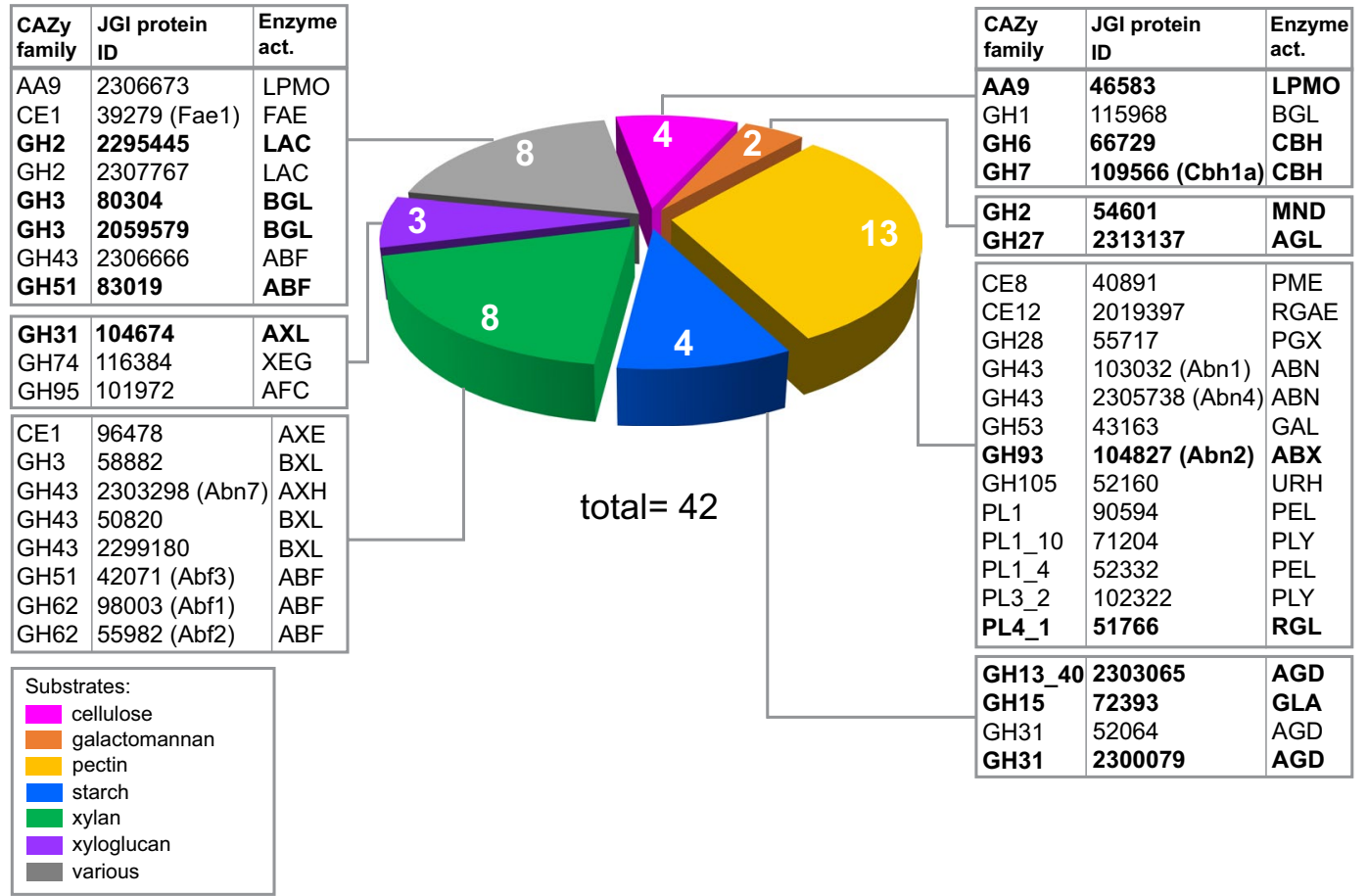

Fig. 6 Up-regulated CAZy genes in the $\triangle M$ txyr 1 strain during 2 and $8 \mathrm{~h}$ of growth on wheat arabinoxylan compared to the wild-type strain. a Up-regulated (>twofold, $p$ value $>0.01$ ) CAZy genes at the $2 \mathrm{~h}$ time point and $\mathbf{b} 8 \mathrm{~h}$ time point in the $\triangle$ Mtxyr 1 strain. In bold, 15 CAZy genes that are up-regulated at both time points. Only the GH, AA, CE or PL families predicted to be involved in plant cell wall degradation per gene are shown. For additional information, i.e., predicted or known enzyme activity abbreviations (Enzyme act.) and the presence of CBM modules, see Additional file 2. In gray (various), the enzymes that act on more than one specific plant polysaccharide

catabolic pathway (PCP) enzymes: D-xylose reductase (Xyl1; JGI: 43671), xylitol dehydrogenase (Xdh1; JGI: 2293953), D-xylulose kinase (Xki1; JGI: 67060) and L-arabinose/D-galacturonic acid reductase (Lar1; JGI: 110022). Transcript levels of two pentose phosphate pathway (PPP) genes, encoding a putative transketolase
(Tkt1; JGI: 2300643) and a ribose-5-phosphate isomerase (Rpi2; JGI: 89872), and four putative glycolytic genes (JGI: 39694, triose-phosphate isomerase; JGI: 84302, an alcohol dehydrogenase; JGI: 2082283, an aldose 1-epimerase and JGI: 2298452, a D-fructose-biphosphate aldolase) were also decreased in $\Delta M t x y r 1$ on D-xylose. 


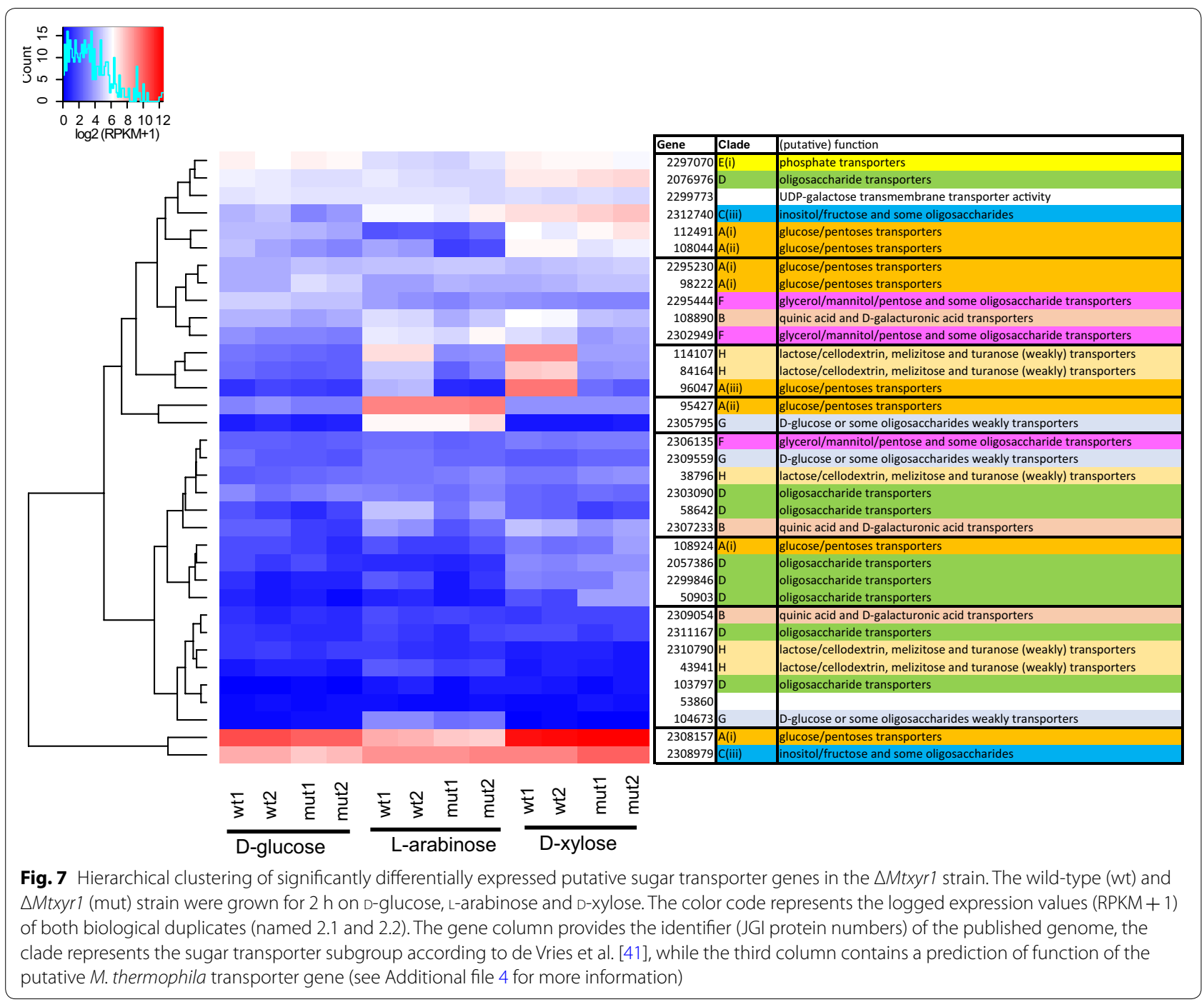

Reduced transcript levels of only five genes were observed in $\Delta M t x y r 1$ on L-arabinose: $x k i 1$, rpi2 and the aldose 1-epimerase gen (JGI: 2082283) and D-fructosebiphosphate aldolase (JGI: 2298452)-encoding genes mentioned above and an aldehyde dehydrogenase gene (JGI: 2140820). The expression of five out of six PCP genes (with the exception of lar1) was induced in the wild type in the presence of L-arabinose or arabinoxylan compared to D-glucose (Additional file 1: Table S1).
Deletion of Mtxyr1 also negatively affected the expression of genes predicted to be involved in the PCP and PPP during 2 and $8 \mathrm{~h}$ of growth on wheat arabinoxylan. Transcript levels of $x y l 1$ were down-regulated at both $2 \mathrm{~h}$ and $8 \mathrm{~h}$, while expression of $x$ ki1 (JGI: 67060) was only down-regulated at $2 \mathrm{~h}$. The transcript levels of two PPP genes, $t k t 1$ (JGI: 2300643) and rpi2 (JGI: 89872), were also decreased in $\Delta$ Mtxyr1 on wheat arabinoxylan after $2 \mathrm{~h}$.

\section{(See figure on next page.)}

Fig. 8 Schematic presentation of the expression of the genes from pentose catabolism. The figure represents a schematic view of the pentose catabolic pathway in which the (putative) M. thermophila genes involved are indicated next to the catalytic step carried out by their corresponding enzymes. The gene names are indicated above the boxes and the corresponding protein numbers from the published JGl genome of this species below the boxes. The boxes themselves reflect the expression of the genes on three substrates (D-glucose, L-arabinose and D-xylose) both in the wild type and the Mtxlr1 mutant. Expression values are expressed as log-scaled RPKM values 


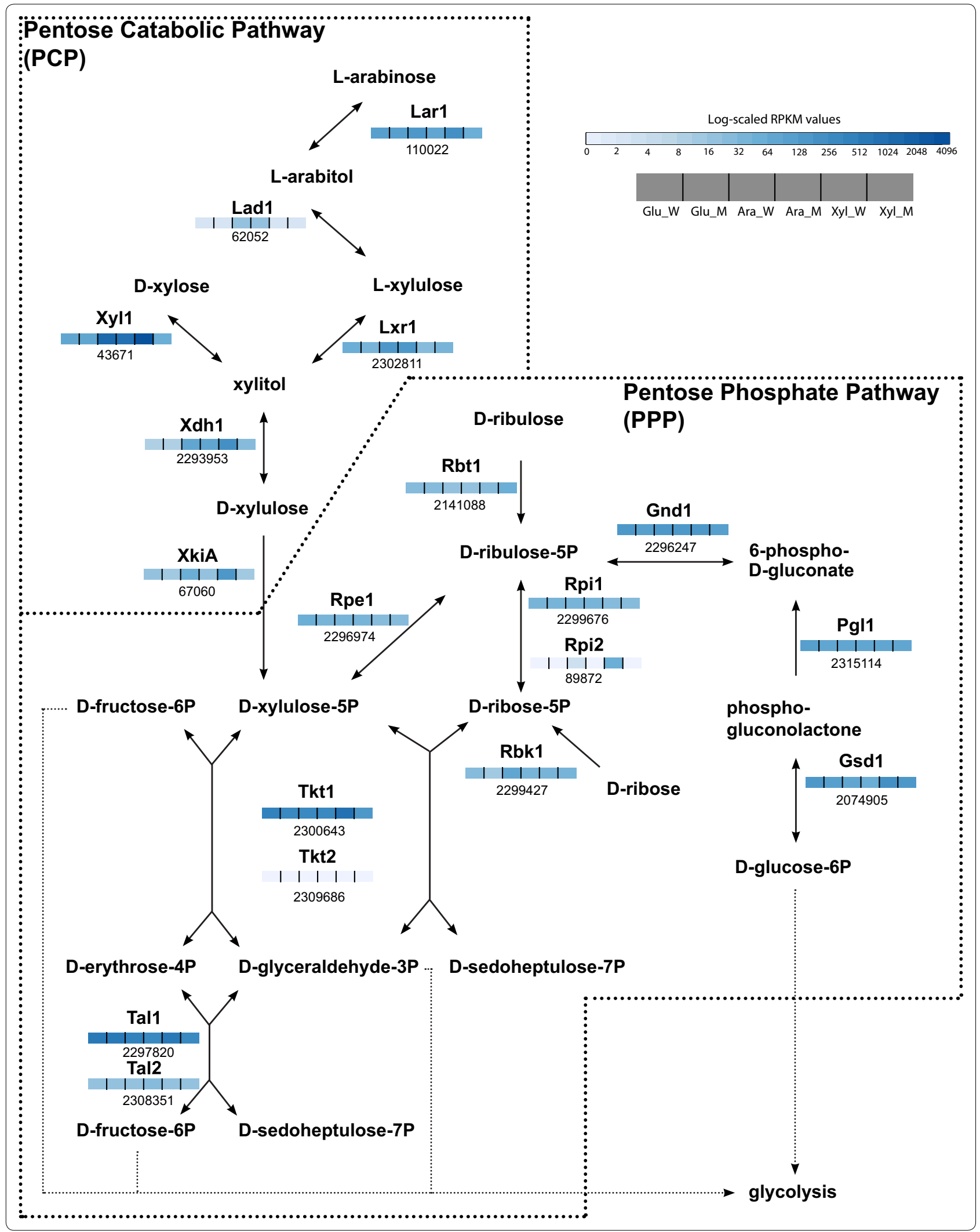


Transcript levels of many genes were observed to be significantly increased in $\Delta M t x y r 1$ after $2 \mathrm{~h}$ and/or $8 \mathrm{~h}$ on wheat arabinoxylan, reflecting metabolism utilizing $\mathrm{L}$-arabinose. These genes are predicted to be involved in central metabolism (i.e., glycolysis and the PPP), the metabolism of D-mannose, the D-galacturonic acid pathway, the L-rhamnose pathway and the Leloir pathway. Transcript levels of lar1 (JGI: 110022), rpi2 (JGI: 89872) and a triose-phosphate isomerase gene (JGI: 39694) were only increased after $8 \mathrm{~h}$ on wheat arabinoxylan in $\Delta$ Mtxyr1.

\section{Discussion}

Fungi have developed complex mechanisms to adjust their carbon metabolism to minimize energy demands. In the presence of easily metabolized carbon sources, such as glucose, the expression of genes necessary for utilization of alternative carbon sources is repressed [42]. DXylose and $\mathbf{L}$-arabinose are important components of the plant cell wall polysaccharides. Those pentoses are able to act as inducers of the expression of genes encoding plant biomass-degrading enzymes, through the regulation of the xylanolytic activator XlnR [26]. This activator (Xyr1 in $M$. thermophila) is not only involved in the regulation of CAZy-encoding genes and a set of sugar transporters, but also contributes to regulation of genes in the pentose catabolic pathway (PCP) and pentose phosphate pathway (PPP) [43-45]. Xyr1 homologs are commonly found in ascomycete fungi. However, induction and regulation of genes involved in xylan and cellulose degradation are significantly different among species [25, 30, 46]. No detailed analysis has been published to date about how this transcription factor regulates the xylanolytic system in the industrially important thermophilic fungal enzyme producer $M$. thermophila. In our present study, we aimed at obtaining a comprehensive understanding of how an xyr1 deletion affects gene expression in this fungal host.

Growth phenotype analysis of the $\Delta M t x y r 1$ strain revealed severely reduced growth on $\mathrm{D}$-xylose and birchwood xylan. Uptake experiments using transfer of fructose pre-grown mycelia showed that D-xylose uptake was impaired in the mutant strain but L-arabinose uptake was only marginally slowed down. This correlates well with the expression results which showed that four genes involved in the PCP (xyl1, xdh1, xki1 and lar1) were significantly down-regulated, suggesting that those genes are under control of Xyr1. This is similar to what was observed in T. reesei where the deletion of Xyr1 showed a strong reduction in growth on D-xylose [47], whereas in that case the whole pathway turned out to be regulated by Xyr1 [29]. In the case of M. thermophila lad 1 and $l x r 1$, the expression levels are not affected by the Xyr1 deletion. A reduced growth on $\mathrm{D}$-xylose associated with a low expression of PCP genes, $x y r 1$, prd1, lad1 and $x d h 1$, was also reported for the $M$. oryzae deletion mutant of Xlr 1 , although this regulator does not control the xylanolytic system [48]. On the other hand, for Aspergillus it has been demonstrated that the growth on D-xylose is only affected when the transcriptional regulators $X \ln R$ and AraR are both deleted [49], suggesting that the regulation of the PCP partially depends on XlnR.

An important response was also observed in the transcription of genes involved in the pentose phosphate pathway. Expression of the ribose 5-phosphate isomerase (rpi2)-encoding gene and a putative transketolase $(t k t 1)$ was significantly lower in the $\Delta M t x y r 1$ mutant upon transfer from fructose to D-xylose, indicating direct regulation by Xyr1. As previously proposed [44], the transcription regulators $\mathrm{X} \ln \mathrm{R}$ and $\mathrm{AraR}$ also regulate some PPP genes in $A$. niger.

Growth of $\Delta M t x y r 1$ on L-arabinose was slightly reduced and a lower expression of $x k i 1$ and rip2 was observed. This could be explained by the small amount of D-xylose present in commercial L-arabinose [50] and this possibly induced Xyr1-regulated genes in the wild type. There is no difference in lad1 and $l x r 1$ expression between the reference strain and the $\Delta M t x y r 1$ mutant representing two steps of the PCP specific for L-arabinose utilization. This is the case both in D-xylose and $\mathrm{L}$-arabinose, indicating that Xyr1 is not involved in $\mathrm{L}$-arabinose utilization.

Reduction in growth on arabinoxylan was also pronounced in $\Delta M$ txyr 1 . The transcript level of $x k i A$ was only down-regulated at the $2 \mathrm{~h}$ time point, while expression of $x y l 1$ decreased at $8 \mathrm{~h}$. Since wheat arabinoxylan is a substrate mainly containing $\mathrm{D}$-xylose and L-arabinose, it is likely that $M$. thermophila takes up D-xylose preferentially, indicating the expected profile of down-regulated Xyr1-dependent genes at early time points. We demonstrated (unpublished results) that when providing a xylose/arabinose mixture, xylose was preferentially taken up during the first $12 \mathrm{~h}$ of growth in the wild type. In the Mtxyr1 deletion strain, D-xylose was hardly taken up but did gradually disappear from the medium in the presence of $\mathrm{L}$-arabinose indicating that uptake of $\mathrm{D}$-xylose requires energy which is provided by the co-substrate.

The question whether Xyr1-dependent transporters are still involved in the slow D-xylose uptake observed under these conditions can only be answered by systematically eliminating these transporters.

Xylanolytic activities present in the culture filtrate were significantly affected in $\Delta M t x y r 1$ after $24 \mathrm{~h}$ of growth on D-xylose, L-arabinose, arabinoxylan and birchwood xylan. Previously, it was shown that overexpression of Xyr1 in $M$. thermophila ATCC 42464 mainly resulted in an increased xylanase activity both in glucose and in 
corncob-containing media. However, the filter paper activity and endoglucanase activities were not affected in corncob- and glucose-containing medium indicating that Xyr 1 plays no or only a limited role in regulating cellulolytic gene expression [31].

To gain insight into the regulation of CAZy genes, the transcriptional responses during growth on D-glucose, D-xylose, L-arabinose and wheat arabinoxylan (2 and $8 \mathrm{~h}$ ) were analyzed in the $\Delta M$ txyr 1 mutant (Fig. 4). Our results demonstrated that Xyr1 is required for the expression of hemicellulolytic genes and a subset of mainly AA9 LPMO genes which are usually considered to play a role in cellulose oxidation. D-xylose activates the expression of these genes (Group 1 and 2).

The xylanolytic genes comprise endo- and exo-acting encoding activities and some auxiliary functions as expected. The difference in expression profile of the genes of Group 2 and Group 1 is most likely due to D-xylose impurities present in $\mathbf{L}$-arabinose in combination with differences in carbon catabolite repression of the target genes. Interestingly, among the genes in Group 1, 6 AA9 LPMOs were found representing a substantial number of the 22 AA9 LPMO genes reported before to be present in the $M$. thermophila genome [10]. A recent study showed that the activity of one of the lytic polysaccharide monooxygenase (MtLPMO9A) from $M$. thermophila $\mathrm{C} 1$ cleaves $\beta-(1 \rightarrow 4)$-xylosyl bonds in xylan, generating oxidized xylo-oligosaccharides, whereas it simultaneously cleaves $\beta$ - $(1 \rightarrow 4)$-glucosyl bonds in cellulose having a synergistic interaction with endoglucanase I [51]. As this specific LPMO is active on xylan, our transcriptomic data suggests that other LPMOs responding to Xyr1 might also be involved in oxidative cleavage of xylan. Additionally, one GH1 $\beta$-glucosidase gene (Group 1), an endo-xyloglucanase and a mannosidase (Group 2) were down-regulated in the presence of D-xylose, showing that at least a few cellulolytic genes are regulated by Xyr1. Similarly, in N. crassa, Xlr-1 is absolutely required for the expression of hemicellulose genes and those involved in D-xylose metabolism, while cellulase genes are slightly affected [52]. It has been reported that two transcription factors CLR-1 and CLR-2 are the predominant regulators of the expression of cellulase-encoding genes in $N$. crassa [24] as is probably the case in M. thermophila. Recently, a new specific regulator MHR1 was identified in M. thermophila ATCC 42464 and the results showed that an Mtmhr1 deletion increased expression of the main cellulase genes (cbh1, cbh2, egl3) and also of xyr1. It is not yet understood whether this regulator has any connection with CRE1 and ACE1 [53].

Expression of two L-arabinofuranosidase genes (abf3, $a b n 4)$ was significantly down-regulated in $\Delta M t x y r 1$ on $\mathbf{L}$-arabinose (Group 3). This indicates that Xyr1 also regulates a few genes of the arabinanolytic system. However, the expression of $a b f 1, a b f 2$ and other arabinanolytic genes is not under control of Xyr1 (Group 4), indicating the requirement of another transcriptional regulator. In Aspergillus, the arabinanolytic regulator AraR controls the expression of genes encoding $\alpha$-arabinofuranosidases (AbfA, AbfB) [54] Our results also show a group of genes involved in cellulose and starch degradation (Group 6) that were significantly up-regulated on D-xylose and are not MtXyr1 dependent.

During the early $2 \mathrm{~h}$ growth phase on wheat arabinoxylan, the majority of xylanolytic genes were down-regulated and a set of genes involved in starch, cellulose and pectin degradation were up-regulated in the $\Delta M t x y r 1$ strain. This might be caused by a compensation effect by other transcription factors that act in a coordinated manner to induce enzymes which would be able to recruit nutrients from other polymers over time.

\section{Conclusions}

Although in the industrial fungi A. niger, A. oryzae and T. reesei, the Xyr1 homolog is involved in regulating the expression of the xylanolytic system and at least part of the cellulolytic system, this is not the case in $M$. thermophila. Xyr1 seems to be predominantly restricted to the xylanolytic system, as confirmed by the extracellular enzyme profiles determined $24 \mathrm{~h}$ after the transfer to the different carbon sources and by the significantly reduced XLN and BXL activities in the Mtxyr 1 deletion mutant. The effects of the Xyr1 deletion at the transcriptome level of the CAZy genes identifies lack or reduced expression of all core activities involved in hydrolyzing xylan.

ABF activity clearly depends on the presence of $\mathbf{L}$-arabinose or on arabinoxylan and expression of the corresponding genes does not require Xyr1, but likely depends on the homolog of the Ara1 activator present in T. reesei and M. oryzae.

The transcriptome analysis upon transfer from fructose to the polysaccharide arabinoxylan carried out after $2 \mathrm{~h}$ and $8 \mathrm{~h}$ illustrates the dynamics of the adaptation process. At the $2 \mathrm{~h}$ time point, there is a considerable overlap both in number and identity between the Xyr1-dependent genes on D-xylose [35] and on arabinoxylan [24] compared with wild-type and the Mtxyr1 deletion strain. The number of strictly Xyr1-dependent genes reduces to ten at the $8 \mathrm{~h}$ time point on arabinoxylan.

\section{Methods}

Strains, media and growth conditions

All Myceliophthora thermophila strains described in this study were grown on malt extract agar (MEA) plates at $37^{\circ} \mathrm{C}$ for 7 days to obtain conidia. For growth phenotypic 
profiling, the WT and $\Delta M$ txyr 1 strain were grown on minimal medium agar plates ( $\mathrm{pH}$ set to 6.0) containing AspA + N (70 mM NaNO $\left.3,7 \mathrm{mM} \mathrm{KCl,} 11 \mathrm{mM} \mathrm{KH}_{2} \mathrm{PO}_{4}\right)$, $2 \mathrm{mM} \mathrm{MgSO}_{4}$, trace elements $(174 \mu \mathrm{M}$ EDTA, $76 \mu \mathrm{M}$ $\mathrm{ZnSO}_{4} \cdot 7 \mathrm{H}_{2} \mathrm{O}, 178 \mu \mathrm{M} \quad \mathrm{H}_{3} \mathrm{BO}_{3}, 25 \mu \mathrm{M} \quad \mathrm{MnSO}_{4} \cdot \mathrm{H}_{2} \mathrm{O}$, $18 \mu \mathrm{M} \quad \mathrm{FeSO}_{4} \cdot 7 \mathrm{H}_{2} \mathrm{O}, 7.1 \mu \mathrm{M} \quad \mathrm{CoCl}_{2} \cdot 6 \mathrm{H}_{2} \mathrm{O}, 6.4 \mu \mathrm{M}$ $\mathrm{CuSO}_{4} \cdot 5 \mathrm{H}_{2} \mathrm{O}$ and $\left.6.2 \mu \mathrm{M} \mathrm{Na}_{2} \mathrm{MoO}_{4} \cdot 2 \mathrm{H}_{2} \mathrm{O}\right), 1.6 \%$ agaragar (Merck Company, Darmstadt, Germany), $10 \mathrm{mM}$ of uridine (if necessary) and $25 \mathrm{mM}$ of D-glucose, D-xylose, $\mathrm{L}$-arabinose or cellobiose or $1 \%$ of birchwood xylan, wheat arabinoxylan, Avicel or cellulose. All sugar substrates were purchased from Sigma-Aldrich (St. Louis, MO, USA), except for cellobiose (Acros Organics, Belgium), wheat arabinoxylan (Megazyme, Wicklow, Ireland) and Avicel (Fluka Chemicals, Buchs, Switzerland). Strains were inoculated with $2 \mu \mathrm{L}$ containing 500 spores and grown for 5 days at $37^{\circ} \mathrm{C}$.

In the sugar consumption experiments, the WT and $\Delta M$ txyrl strains were pre-grown in complete medium (pH 6.0) containing AspA $+\mathrm{NH}_{4}\left(35 \mathrm{mM}\left(\mathrm{NH}_{4}\right)_{2} \mathrm{SO}_{4}\right.$, $7 \mathrm{mM} \mathrm{NaCl}, 55 \mathrm{mM} \mathrm{KH_{2 }} \mathrm{PO}_{4}$ ), $2 \mathrm{mM} \mathrm{MgSO}$, trace elements (as described above), $0.1 \%$ casamino acids, $4 \mu \mathrm{g} / \mathrm{L}$ biotin and $2 \%$ fructose buffered with extra addition of $70 \mathrm{mM} \mathrm{KH} \mathrm{PO}_{4}$. The strains were inoculated with $1 \cdot 10^{5}$ spores per $\mathrm{mL}$ and the liquid cultures were incubated at $37^{\circ} \mathrm{C}$ at $200 \mathrm{rpm}$ in a rotary shaker. After $36 \mathrm{~h}$ of incubation, the mycelium was then transferred into shake flasks with minimal medium by filtering the pre-culture medium through Miracloth. The mycelium was quickly washed with minimal medium without sugar and approximately $1.0 \mathrm{~g}$ (wet weight) of mycelium was transferred to $50 \mathrm{~mL}$ liquid shake flask cultures. Minimal medium $(\mathrm{pH}$ 6.0) contained AspA $+\mathrm{NH}_{4}, 2 \mathrm{mM} \mathrm{MgSO}$, trace elements, $0.1 \%$ casamino acids, $4 \mu \mathrm{g} / \mathrm{L}$ biotin and was buffered with $70 \mathrm{mM} \mathrm{KH_{2 }} \mathrm{PO}_{4}$. In addition, $1 \% \mathrm{D}$-xylose or L-arabinose or a mixture of the both sugars $(0.5 \%$ of each sugar) was added to the minimal medium. The liquid shake flasks were incubated at $37{ }^{\circ} \mathrm{C}$ at $200 \mathrm{rpm}$ for $48 \mathrm{~h}$ and $2 \mathrm{~mL}$ medium samples were collected after $4,8,12$, 24,33 and $48 \mathrm{~h}$.

For the extracellular activity measurements, the $\mathrm{WT}$ and $\Delta M t x y r 1$ strains were pre-grown in complete medium ( $\mathrm{pH}$ 6.0) containing AspA + N, $2 \mathrm{mM} \mathrm{MgSO}_{4}$, trace elements, $0.1 \%$ casamino acids, $5 \mathrm{~g} / \mathrm{L}$ yeast extract, $4 \mu \mathrm{g} / \mathrm{L}$ biotin and $1 \%$ D-glucose. Strains were inoculated with $1 \cdot 10^{5}$ spores per $\mathrm{mL}$ and incubated at $37^{\circ} \mathrm{C}$ at $200 \mathrm{rpm}$ in a rotary shaker. After $36 \mathrm{~h}$ of incubation, precultures were filtered using Miracloth, the mycelium was washed with the respective complete medium (without carbon source) and aliquots of wet mycelium were transferred to liquid shake flasks with minimal medium and as a carbon source $1 \%$ of D-glucose, D-xylose, L-arabinose, cellobiose, Avicel, wheat arabinoxylan or birchwood xylan, respectively, as described above and sampled after $24 \mathrm{~h}$. Minimal medium ( $\mathrm{pH}$ 6.0) containing AspA $+\mathrm{NH}_{4}$, $2 \mathrm{mM} \mathrm{MgSO}_{4}$, trace elements, $0.1 \%$ casamino acids and $4 \mu \mathrm{g} / \mathrm{L}$ biotin was buffered by an extra addition of $70 \mathrm{mM}$ $\mathrm{KH}_{2} \mathrm{PO}_{4}$.

For RNA-seq analysis, the WT and $\Delta M t x y r 1$ strain were pre-grown in complete medium $(\mathrm{pH}$ 6.0) containing AspA $+\mathrm{NH}_{4}, 2 \mathrm{mM} \mathrm{MgSO}$, trace elements, $0.1 \%$ casamino acids, $4 \mu \mathrm{g} / \mathrm{L}$ biotin and $2 \% \mathrm{D}$-fructose. Strains were inoculated with $1 \cdot 10^{6}$ spores per $\mathrm{mL}$ and incubated at $37{ }^{\circ} \mathrm{C}$ at $200 \mathrm{rpm}$ in a rotary shaker. After $36 \mathrm{~h}$ of incubation, aliquots of the mycelium were transferred to shake flasks with minimal medium and as a carbon source $25 \mathrm{mM}$ of D-glucose, D-xylose or L-arabinose or $1 \%$ wheat arabinoxylan, respectively. Minimal medium ( $\mathrm{pH}$ 6.0) contained AspA $+\mathrm{NH}_{4}, 2 \mathrm{mM} \mathrm{MgSO}$, trace elements, $0.1 \%$ casamino acids and $4 \mu \mathrm{g} / \mathrm{L}$ biotin and was buffered by an extra addition of $70 \mathrm{mM} \mathrm{K \textrm {H } _ { 2 }} \mathrm{PO}_{4}$. Mycelial samples were harvested after $2 \mathrm{~h}$ of incubation in all monosaccharide cultures and after 2 and $8 \mathrm{~h}$ of incubation in case of the wheat arabinoxylan culture. The mycelial samples were dried between tissue paper and directly frozen in liquid nitrogen for RNA extraction.

\section{Molecular biology methods}

The deletion cassette used to create the M. thermophila $\Delta x y r 1$ strain was constructed by fusion PCR. To delete Mtxyr1 gene, the ORF was replaced by the coding sequence of the $M$. thermophila pyr 5 gene in the uridine $\mathrm{C} 1$ auxotrophic host strain $\left(\right.$ pyr $\left.^{-}\right)$. In the first PCR reactions, the upstream (fragment 1; F1) and downstream (fragment 2; F2) flanking genomic region of the $x l r 1$ gene, and the pyr5 gene (fragment 3; F3) were amplified from C1 WT genomic DNA (Additional file 1: Fig. S1).

PCRs were performed using GoTaq ${ }^{\circledR}$ Long PCR Master Mix (Promega, Madison, WI). To obtain the three fragments, all PCRs were prepared by using $12.5 \mu \mathrm{L}$ of GoTaq Master Mix, $0.24 \mu \mathrm{M}$ primer concentrations, $5 \mu \mathrm{g}$ of template DNA (genomic M. thermophila DNA) and nuclease-free water to adjust the volume to $25 \mu \mathrm{L}$. The PCR conditions were as follows: DNA polymerase activation at $95{ }^{\circ} \mathrm{C}$ for 2 min was followed by 35 cycles of DNA melting at $94{ }^{\circ} \mathrm{C}$ for $30 \mathrm{~s}$, annealing at $60{ }^{\circ} \mathrm{C}$ (F1 and $\mathrm{F} 2$ primer pairs) or $64{ }^{\circ} \mathrm{C}$ (F3 primer pair) for $30 \mathrm{~s}$, extension at $72{ }^{\circ} \mathrm{C}$ at $1 \mathrm{~kb}$ per $60 \mathrm{~s}$ and with a final extension at $72{ }^{\circ} \mathrm{C}$ for $5 \mathrm{~min}$. The flanking fragment $\mathrm{F} 1$ was amplified using the primer pair xyr1-5'_F (CTA CTCCACGACTCCGTACTTGG) and $x y r 1-5^{\prime} \_\mathrm{R}$ (ggacagcacctgcgcgttgcctgccatggTGGAGATGGGGTCGT CAAGACC), containing the overlapping region with the pyr 5 gene in lowercase letters. The flanking fragment F2 was amplified using the primer pair $x y r 1-3^{\prime}{ }_{-} \mathrm{F}$ (gaagcgaagcaaagtctccgtcgacCTCCTCGTGTGTAAC 
CGTGGG), containing the overlapping region with the pyr5 gene in lowercase letters, and $x y r 1-3^{\prime}{ }_{-} \mathrm{R}$ (GCC ACGACTTTGAGAAGCTCCC). The pyr5 fragment F3 was amplified using the primer pair pyr5_F (CCA TGGCAGGCAACGCGCAG) and pyr5_R (GTCGAC GGAGACTTTGCTTCGCTTC). The fusion PCR was prepared by using $12.5 \mu \mathrm{L}$ of GoTaq Master Mix, $0.24 \mu \mathrm{M}$ primer concentrations (primer pair $x y r 1-5^{\prime} \_\mathrm{F}$ and $x y r 1-3^{\prime} \_$R), the three unpurified PCR products in a mixture at equal concentrations (1:1:1 molar ratio) and nuclease-free water to adjust the volume to $25 \mu \mathrm{L}$. The PCR conditions were as follows: $95^{\circ} \mathrm{C}$ for 2 min was followed by 35 cycles of DNA melting at $94{ }^{\circ} \mathrm{C}$ for $30 \mathrm{~s}$, annealing at $65{ }^{\circ} \mathrm{C}$ or $30 \mathrm{~s}$, extension at $72{ }^{\circ} \mathrm{C}$ at $1 \mathrm{~kb}$ per $60 \mathrm{~s}$ and with a final extension at $72{ }^{\circ} \mathrm{C}$ for $5 \mathrm{~min}$. The fusion PCR product (Mtxyr1 deletion cassette) was purified using the Wizard ${ }^{\circledR}$ SV Gel and PCR CleanUp System (Promega, Madison, WI) and ligated into the pJET1.2/blunt cloning vector using the CloneJET PCR Cloning Kit (Thermo Fisher Scientific, Waltham, MA, USA) according to the manufacturer's sticky-end protocol.

After co-transformation of the M. thermophila C1 pyr $5^{-}$strain with the Mtxyr1 deletion cassette (see next paragraph), deletion of the $x$ lr 1 gene was checked by PCR screening (Additional file 1: Fig. S1). Genomic DNA was obtained from three independent single deletion transformants (DMtxyr1.1, $\Delta M$ txyr1.2 and $\Delta M$ txyr1.3). The PCR screen was performed using GoTaq ${ }^{\circledR}$ Flexi DNA Polymerase (Promega, Madison, WI). The PCRs were prepared by using $5 \mu \mathrm{L}$ of GoTaq $^{\circledR}$ Flexi buffer, $1.0 \mu \mathrm{M}$ $\mathrm{MgCl}_{2}, 0.20 \mu \mathrm{M}$ of primer concentrations, $0.2 \mathrm{mM}$ each dNTP, 20 ng of template DNA (genomic M. thermophila DNA), $0.125 \mu \mathrm{L}$ of GoTaq $^{\circledR}$ Flexi polymerase and nuclease-free water to adjust the volume to $25 \mu \mathrm{L}$. The PCR conditions were as follows: $95{ }^{\circ} \mathrm{C}$ for 2 min was followed by 30 cycles of DNA melting at $94{ }^{\circ} \mathrm{C}$ for $30 \mathrm{~s}$, annealing at $62{ }^{\circ} \mathrm{C}$ for $30 \mathrm{~s}$, extension at $72{ }^{\circ} \mathrm{C}$ at $1 \mathrm{~kb}$ per $60 \mathrm{~s}$ and with a final extension at $72{ }^{\circ} \mathrm{C}$ for $5 \mathrm{~min}$. The presence of the ORF of xlr1 was checked using the primers pair ORF_F (CAGGAAAGACCTTGCACAGC) and ORF_R (CACGGAAGTTACCGTTCTGG). The $5^{\prime}$ region of the xlr1 deletion cassette was amplified using the primer pair DC5_F (TCAGGACAGCGTACAAGTAGTGG) and DCpyr5_R (GTGCTCCCTATCTGACAACTCC). The $3^{\prime}$ region was amplified using the primer pair DCpyr5_F (GCACAGCATCTCTTGAAGCG) and DC3_R (CTG CTTGATGCTCGATATGC).

One of gene deletion mutants ( $\Delta M t x y r 1.1$ strain) was complemented with the wild-type gene copy, and a complementation vector was constructed containing the ORF of the $x y r 1$ gene with a 2000 bp promoter region and $1500 \mathrm{bp}$ terminator region. The amplified PCR product was ligated into the pJET1.2/blunt cloning vector using the CloneJET PCR Cloning Kit (Thermo Fisher Scientific, Waltham, MA, USA) according to the manufacturer's instructions.

\section{Myceliophthora thermophila transformation}

About $10^{6}$ spores per $\mathrm{mL}$ were inoculated into $250 \mathrm{~mL}$ of complete medium ( $\mathrm{pH}$ 6.0) containing AspA $+\mathrm{NH}_{4}$ (35 mM $\left(\mathrm{NH}_{4}\right)_{2} \mathrm{SO}_{4}, 7 \mathrm{mM} \mathrm{NaCl}, 55 \mathrm{mM} \mathrm{KH} \mathrm{KO}_{4}$ ), $2 \mathrm{mM} \mathrm{MgSO}_{4}$, trace elements (as described above), $0.1 \%$ casamino acids, $4 \mu \mathrm{g} / \mathrm{L}$ biotin and $2 \%$ fructose buffered with extra addition of $70 \mathrm{mM} \mathrm{KH_{2 }} \mathrm{PO}_{4}$ and cultured at $37{ }^{\circ} \mathrm{C}$ at $200 \mathrm{rpm}$ for $24 \mathrm{~h}$. Young mycelia were harvested by vacuum filtration and washed with $100 \mathrm{~mL} \mathrm{NaCl} /$ $\mathrm{CaCl}_{2}\left(0.6 \mathrm{M} \mathrm{NaCl}, 0.27 \mathrm{M} \mathrm{CaCl}_{2} 2 \mathrm{H}_{2} \mathrm{O}\right)$. About $2 \mathrm{~g}$ of mycelium was then dissolved in a protoplasting enzyme mix (20 mg Lysing Enzymes Trichoderma harzianum, $15 \mathrm{mg}$ Driselase from Basidiomycetes sp. per gram of mycelium dissolved in $5 \mathrm{~mL}$ of $\mathrm{NaCl} / \mathrm{CaCl}_{2}$ ) and incubated in a rotary shaker at $70 \mathrm{rpm}$ at $30^{\circ} \mathrm{C}$. When enough protoplasts were formed, the mixture was filtered over a sterile Miracloth and washed with $22.5 \mathrm{~mL} \mathrm{NaCl} / \mathrm{CaCl}_{2}$. Next, $22.5 \mathrm{~mL}$ of cold STC (1.2 M sorbitol, $50 \mathrm{mM} \mathrm{CaCl}_{2}$. $\mathrm{H}_{2} \mathrm{O}, 35 \mathrm{mM} \mathrm{NaCl}, 10 \mathrm{mM}$ Tris/ $\mathrm{HCl}$ ) was added to the suspension and mixed by gently inverting the tube a couple of times. The protoplasts were collected by centrifugation $\left(10 \mathrm{~min}, 2500 \mathrm{rpm}, 4{ }^{\circ} \mathrm{C}\right)$, resuspended in $50 \mathrm{~mL}$ of STC and centrifuged again. The supernatant was discarded and the pellet was carefully resuspended in the remaining STC (approximately $2 \mathrm{~mL}$ ). For transformation, $100 \mu \mathrm{L}$ of protoplast suspension, $1 \mu \mathrm{L}$ of $0.5 \mathrm{M}$ ATA (aurintricarboxylic acid ammonium salt) was mixed with $5 \mu \mathrm{g}$ of deletion cassette DNA and incubated for $25 \mathrm{~min}$. With a $10 \mathrm{~mL}$ pipette 8,8 and 18 drops of $60 \%$ PEG4000 (60\% PEG4000, $50 \mathrm{mM} \mathrm{CaCl} 22_{2} \mathrm{O}, 35 \mathrm{mM} \mathrm{NaCl}$, $10 \mathrm{mM}$ Tris/HCl, $1 \mathrm{M}$ Tris/HCl, $\mathrm{pH}$ 7.5) were added to the suspension and mixed gently by slowly inverting the tube between every step. After 20 min of incubation at room temperature, $50 \mathrm{~mL}$ of STC was added and centrifuged $\left(10 \mathrm{~min}, 2500 \mathrm{rpm}, 4^{\circ} \mathrm{C}\right)$. The supernatant was removed and resuspended in the STC left over. Aliquots $(0.1-0.3 \mathrm{~mL})$ of transformed protoplast suspension were spread over selection plates containing $10 \mathrm{mM}$ of uridine. Growing colonies were observed after 3 days at $37^{\circ} \mathrm{C}$.

\section{Sugar consumption and enzyme activity analysis}

HPLC was used to determine the sugar concentrations in the medium samples collected after 4, 8, 12, 24, 33 and $48 \mathrm{~h}$. Sugar analysis was performed as described previously on a Thermo Scientific 5000 + HPLC-PAD system [55]. The data obtained are the results of two independent biological replicates and for each replicate three technical replicates were assayed. Endo- and exo-acting 
enzyme activities in culture filtrates of transferred mycelia of the $M$. thermophila WT and $\Delta M$ txyr1 strain to liquid shake flask cultures with lignocellulose-related substrates were measured using $p$ NP- ( $p$-nitrophenol) linked substrates (Sigma-Aldrich, St. Louis, MO, USA) to measure $\alpha$-arabinofuranosidase, $\beta$-xylosidase, $\beta$-glucosidase and cellobiohydrolase activity. Azo-CMcellulose and Azo-wheat arabinoxylan (Megazyme, Wicklow, Ireland) were used to measure endo-glucanase or endo-xylanase activity, respectively. Exo-acting enzyme activities were determined by measuring the amount of $p$ NP released after $30-60$ min by the culture filtrate with the $p$ NP-linked substrates and standardized against a known concentration of $p$ NP. Activities are expressed in $\mathrm{mU} / \mathrm{mL}$. The reactions contained between $5 \mu \mathrm{L}$ and $30 \mu \mathrm{L}$ of culture filtrate, $10 \mu \mathrm{L} 0.1 \%$ pNP-linked substrate and $25 \mathrm{mM}$ sodium acetate buffer, $\mathrm{pH}$ 5.0, in a total volume of $100 \mu \mathrm{L}$. All reactions were pipetted and mixed in a 96-wells microtiter plate, incubated at $50{ }^{\circ} \mathrm{C}$ and then stopped by the addition of $100 \mu \mathrm{L} 0.25 \mathrm{M}$ sodium carbonate. Absorbance was measured at $405 \mathrm{~nm}$ in a microtiter plate reader (FLUOstar OPTIMA, BMG Labtech). Endo-acting enzyme activities were measured in $100 \mu \mathrm{L}$ reactions as described previously [56]. Absorbance was measured at $590 \mathrm{~nm}$. Activities are expressed as $\mathrm{mU} / \mathrm{mL}$. All the enzyme activity data obtained are the results of two independent biological replicates and two technical replicates.

\section{RNA extraction and gene expression analysis}

Total RNA was extracted from mycelium ground in a Tissue Lyser II (Qiagen, Venlo, the Netherlands) using TRIzol reagent (Invitrogen, Breda, the Netherlands) and purified with NucleoSpin ${ }^{\circledR}$ RNA II Clean-up kit (Macherey-Nagel) with rDNase treatment. The RNA quantity and quality were checked with an RNA6000 Nano Assay using the Agilent 2100 Bioanalyzer (Agilent Technologies, Santa Clara, CA, USA). RNA samples were singleend sequenced at BGI Tech Solutions Co., Ltd. (Hong Kong, China) using the Illumina HiSeqTM 2000 platform (http://illumina.com). Raw reads were produced from the original image data by base calling. On average, $49 \mathrm{bp}$ sequenced reads were constituted, producing $596 \mathrm{MB}$ raw yields for each sample. After data filtering, the adaptor sequences, reads with unknown bases $(N)>10 \%$ and low-quality reads (more than $50 \%$ of the bases with quality value $<5 \%$ ) were removed. Clean reads were mapped to the genome sequence of $M$. thermophila $v 2.0$ [17] using BWA/Bowtie $[57,58]$ with no more than two mismatches allowed in the alignment. On average, $90 \%$ of the clean reads were mapped to the genome. The gene expression level as reads per kilobase of exon per million fragments mapped (RPKM) was calculated by using the
RSEM tool [59]. Differential expression was identified by CyberT Bayesian ANOVA algorithm [60]. A fold change of $>2$ and $p$ value of $<0.01$ were used to identify differentially expressed genes. The heat maps were made by the "gplots" package of R software, with the default parameters: "Complete-linkage clustering method and Euclidean distance".

The CAZymes and sugar transporter genes were extracted from the $M$. thermophila genome available online at the JGI MycoCosm database, https://genom e.jgi.doe.gov/Spoth2 [61]. The carbon metabolism genes were identified by orthologous mapping with the well annotated genes in the Aspergillus Genome Database (http://www.aspergillusgenome.org/ [62] using a bidirectional best hit $(\mathrm{BBH})$ method $[63,64]$.

\section{Supplementary information}

Supplementary information accompanies this paper at https://doi. org/10.1186/s13068-019-1556-y.

Additional file 1. Combines Table S1 and Figure S1-S4.

Additional file 2. Differentially expressed CAZy genes involved in plant cell wall degradation.

Additional file 3. Differentially expressed genes involved in sugar transport.

Additional file 4. Differentially expressed genes involved in primary metabolism.

Acknowledgements

The authors thank Joost van den Brink for technical advice.

Authors' contributions

RPdV designed the study. DF, EB, MNdA and NCL performed the experiments. $A C d S G, D F, E B, M P, J V$ and RPdV contributed to data analysis and writing of the manuscript. RPdV, JV and J-PM supervised the work. All authors read and approved the final manuscript.

Funding

ACdS was supported by Grant Nr. 88881.131547/2016-01 from the Coordination for the Improvement of Higher Education Personnel (CAPES/PDSE), Brazil. MNdA and DF were supported by Grants Nr. 246743/2012-3 and 246763/2012-4, respectively, of the Conselho Nacional de Desenvolvimento Científico e Tecnológico (CNPQ), Brazil. ACdSG was supported by the Coordination for the Improvement of Higher Education Personnel (CAPES/PDSE) through Grant 88881.131547/2016-01. NCL was supported by Grant 263888 from the National Council of Science and Technology of Mexico. EB was supported by a BE-Basic (The Netherlands) Grant TKIBE01003 to RPdV.

\section{Availability of data and materials}

The datasets generated and analyzed during the current study were deposited at the Gene Expression Omnibus (GEO) database [65] with Accession Number: GSE137286.

Ethics approval and consent to participate Not applicable.

Consent for publication

Not applicable.

Competing interests

The authors declare that they have no competing interests. 


\section{Author details}

${ }^{1}$ Fungal Physiology, Westerdijk Fungal Biodiversity Institute \& Fungal Molecular Physiology, Utrecht University, Uppsalalaan 8, 3584 CT Utrecht, The Netherlands. ${ }^{2}$ Present Address: Novozymes Latin America, Professor Francisco Ribeiro Street 683, Araucária, PR 83707-660, Brazil. ${ }^{3}$ DuPont Industrial Biosciences, Archimedesweg 30, 2333 CN Leiden, The Netherlands. ${ }^{4}$ Present Address: Federal University of São João del Rei, Praça Dom Helvécio, 74, São João del Rei, Minas Gerais, Brazil. ${ }^{5}$ Present Address: Dutch DNA Biotech BV, Padualaan 8, 3584 CH Utrecht, The Netherlands.

\section{Received: 18 April 2019 Accepted: 31 August 2019}

\section{Published online: 16 September 2019}

\section{References}

1. Ghatak H. Biorefineries from the perspective of sustainability: feedstocks, products, and processes. Renew Sust Energy Rev. 2011;15(8):4042-52.

2. van der Weijde T, Alvim Kamei CL, Torres AF, Vermerris W, Dolstra O, Visser $\mathrm{RG}$, et al. The potential of C4 grasses for cellulosic biofuel production. Front Plant Sci. 2013;4(107):1-18.

3. Sarkar N, Ghosh S, Bannerjee S, Aikat K. Bioethanol production from agricultural wastes: an overview. Renew Energy. 2012;37(1):19-27.

4. Himmel ME, Ding SY, Johnson DK, Adney WS, Nimlos MR, Brady JW, et al. Biomass recalcitrance: engineering plants and enzymes for biofuels production. Science. 2007;315(5813):804-7.

5. Sun Y, Cheng J. Hydrolysis of lignocellulosic materials for ethanol production: a review. Bioresour Technol. 2002;83(1):1-11.

6. Van Dyk JS, Pletschke Bl. A review of lignocellulose bioconversion using enzymatic hydrolysis and synergistic cooperation between enzymesfactors affecting enzymes, conversion and synergy. Biotechnol Adv. 2012;30(6):1458-80.

7. Yeoman C, Han Y, Dodd D, Schroeder C, Mackie R, Cann I. Thermostable enzymes as biocatalysts in the biofuel industry. Adv Appl Microbiol. 2010;70:1-55

8. Viikari L, Alapuranen M, Puranen T, Vehmaanpera J, Siika-Aho M. Thermostable enzymes in lignocellulose hydrolysis. Adv Biochem Eng Biotechnol. 2007; 108:121-45.

9. Turner P, Mamo G, Karlsson EN. Potential and utilization of thermophiles and thermostable enzymes in biorefining. Microb Cell Fact. 2007;6:9.

10. Berka RM, Grigoriev IV, Otillar R, Salamov A, Grimwood J, Reid I, et al. Comparative genomic analysis of the thermophilic biomass-degrading fungi Myceliophthora thermophila and Thielavia terrestris. Nat Biotechnol. 2011;29(10):922-7.

11. Bhat KM, Maheshwari R. Sporotrichum thermophile growth, cellulose degradation, and cellulase activity. Appl Environ Microbiol. 1987;53(9):2175-82.

12. Bhat KM, Gaikwad JS, Maheshwari R. Purification and characterization of an extracellular $\beta$-glucosidase from the thermophilic fungus Sporotrichum thermophile and its influence on cellulase activity. Microbiol. 1993:139:2825-32.

13. Karnaouri A, Topakas E, Antonopoulou I, Christakopoulos P. Genomic insights into the fungal lignocellulolytic system of Myceliophthora thermophila. Front Microbiol. 2014;5:281.

14. Katsimpouras C, Dimarogona M, Petropoulos P, Christakopoulos P, Topakas E. A thermostable GH26 endo-beta-mannanase from Myceliophthora thermophila capable of enhancing lignocellulose degradation. Appl Microbiol Biotechnol. 2016;100(19):8385-97.

15. Gusakova A, Sinitsyna A, Salanovicha T, Bukhtojarova F, Markova A, Ustinova B, et al. Purification, cloning and characterisation of two forms of thermostable and highly active cellobiohydrolase I (Cel7A) produced by the industrial strain of Chrysosporium lucknowense. Enzyme Microb Technol. 2005;36(1):57-69.

16. Ustinov BB, Gusakov AV, Antonov Al, Sinitsyn AP. Comparison of properties and mode of action of six secreted xylanases from Chrysosporium lucknowense. Enzyme Microb Technol. 2008;43(1):56-65.

17. Bukhtojarov FE, Ustinov BB, Salanovich TN, Antonov Al, Gusakov AV, Okunev ON, et al. Cellulase complex of the fungus Chrysosporium lucknowense: isolation and characterization of endoglucanases and cellobiohydrolases. Biochem Biokhim. 2004;69(5):542-51.
18. Hinz SW, Pouvreau L, Joosten R, Bartels J, Jonathan MC, Wery J, et al. Hemicellulase production in Chrysosporium lucknowense C1. J Cereal Sci. 2009;50(3):318-23.

19. Kolbusz MA, Di Falco M, Ishmael N, Marqueteau S, Moisan MC, Baptista Cda S, et al. Transcriptome and exoproteome analysis of utilization of plant-derived biomass by Myceliophthora thermophila. Fungal Genet Biol. 2014;72:10-20.

20. Matsakas L, Antonopoulou I, Christakopoulos P. Evaluation of Myceliophthora thermophila as an enzyme factory for the production of thermophilic cellulolytic enzymes. BioResources. 2015;10(3):5140-58.

21. Sugden C, Bhat MK. Cereal straw and pure cellulose as carbon sources for growth and production of plant cell-wall degrading enzymes by Sporotrichum thermophile. World J Microbiol Biotechnol. 1994;10(4):444-51.

22. van den Brink J, van Muiswinkel GC, Theelen B, Hinz SW, de Vries RP. Efficient plant biomass degradation by thermophilic fungus Myceliophthora heterothallica. Appl Environ Microbiol. 2013;79(4):1316-24.

23. Visser H, Joosten V, Punt PJ, Gusakov AV, Olson PT, Joosten R, et al. Development of a mature fungal technology and production platform for industrial enzymes based on a Myceliophthora thermophila isolate, previously known as Chrysosporium lucknowense C1. Ind Biotechnol. 2011;7(3):214-23.

24. Coradetti ST, Craig JP, Xiong Y, Shock T, Tian C, Glass NL. Conserved and essential transcription factors for cellulase gene expression in ascomycete fungi. Proc Nat Acad Sci USA. 2012;109(19):7397-402.

25. Klaubauf S, Narang HM, Post H, Zhou M, Brunner K, Mach-Aigner AR, et al. Similar is not the same: differences in the function of the (hemi-) cellulolytic regulator XInR (XIr1/Xyr1) in filamentous fungi. Fungal Genet Biol. 2014;72:73-81.

26. van Peij NN, Visser J, de Graaff LH. Isolation and analysis of $x \ln R$, encoding a transcriptional activator co-ordinating xylanolytic expression in Aspergillus niger. Mol Microbiol. 1998;27(1):131-42.

27. Gielkens MM, Dekkers E, Visser J, de Graaff LH. Two cellobiohydrolaseencoding genes from Aspergillus niger require D-xylose and the xylanoIytic transcriptional activator XInR for their expression. Appl Environ Microbiol. 1999;65(10):4340-5.

28. Noguchi Y, Sano M, Kanamaru K, Ko T, Takeuchi M, Kato M, et al. Genes regulated by AoXInR, the xylanolytic and cellulolytic transcriptional regulator, Aspergillus oryzae. Appl Microbiol Biotechnol. 2009;85(1):141-54.

29. Stricker $A R, M a c h ~ R L$, de Graaff $L H$. Regulation of transcription of cellulases- and hemicellulases-encoding genes in Aspergillus niger and Hypocrea jecorina (Trichoderma reesei). Appl Microbiol Biotechnol. 2008;78(2):211-20.

30. Craig JP, Coradetti ST, Starr TL, Glass NL. Direct target network of the Neurospora crassa plant cell wall deconstruction regulators CLR-1, CLR-2, and XLR-1. MBio. 2015;6(5):e01452-15.

31. Wang J, Wu Y, Gong Y, Yu S, Liu G. Enhancing xylanase production in the thermophilic fungus Myceliophthora thermophila by homologous overexpression of Mtxyr1. J Ind Microbiol Biotechnol. 2015;42(9):1233-41.

32. Khosravi C, Battaglia E, Kun RS, Dalhuijsen S, Visser J, Aguilar-Pontes MV, et al. Blocking hexose entry into glycolysis activates alternative metabolic conversion of these sugars and upregulates pentose metabolism in Aspergillus nidulans. BMC Genomics. 2018;19:214.

33. Frommhagen M, Koetsier MJ, Westphal AH, Visser J, Hinz SW, Vincken JP, et al. Lytic polysaccharide monooxygenases from Myceliophthora thermophila C1 differ in substrate preference and reducing agent specificity. Biotechnol Biofuels. 2016;9(1):186.

34. Kuhnel S, Hinz SW, Pouvreau L, Wery J, Schols HA, Gruppen H. Chrysosporium lucknowense arabinohydrolases effectively degrade sugar beet arabinan. Bioresour Technol. 2010;101(21):8300-7.

35. Kuhnel S, Pouvreau L, Appeldoorn MM, Hinz SW, Schols HA, Gruppen H. The ferulic acid esterases of Chrysosporium lucknowense C1: purification, characterization and their potential application in biorefinery. Enzyme Microbial Technol. 2012;50(1):77-85.

36. Pouvreau L, Jonathan MC, Kabel MA, Hinz SW, Gruppen H, Schols HA. Characterization and mode of action of two acetyl xylan esterases from Chrysosporium lucknowense $\mathrm{C} 1$ active towards acetylated xylans. Enzyme Microbial Technol. 2011;49(3):312-20.

37. Colabardini AC, Ries LN, Brown NA, Dos Reis TF, Savoldi M, Goldman MH, et al. Functional characterization of a xylose transporter in Aspergillus nidulans. Biotechnol Biofuels. 2014;7(1):46. 
38. Sloothaak J, Schilders M, Schaap PJ, de Graaff LH. Overexpression of the Aspergillus niger GatA transporter leads to preferential use of D-galacturonic acid over D-xylose. AMB Express. 2014;4:66.

39. Cai P, Gu R, Wang B, Li J, Wan L, Tian C, et al. Evidence of a critical role for cellodextrin transporte 2 (CDT-2) in both cellulose and hemicellulose degradation and utilization in Neurospora crassa. PLoS ONE. 2014;9(2):e89330.

40. Li X, Yu VY, Lin Y, Chomvong K, Estrela R, Park A, et al. Expanding xylose metabolism in yeast for plant cell wall conversion to biofuels. eLife. 2015;4:e05896.

41. de Vries RP, Riley R, Wiebenga A, Aguilar-Osorio G, Amillis S, Uchima CA, et al. Comparative genomics reveals high biological diversity and specific adaptations in the industrially and medically important fungal genus Aspergillus. Genome Biol. 2017;18(1):28.

42. Ruijter GJG, Visser J. Carbon repression in Aspergilli. FEMS Microbiol Lett. 1997;151:103-14.

43. Battaglia E. Regulation and diversity of plant polysaccharide utilisation in fungi [PhD Dissertation]. Utrecht: University Utrecht; 2011.

44. Battaglia E, Zhou M, de Vries RP. The transcriptional activators AraR and XInR from Aspergillus niger regulate expression of pentose catabolic and pentose phosphate pathway genes. Res Microbiol. 2014;165(7):531-40.

45. Witteveen CFB, Busink R, van de Vondervoort P, Dijkema C, Swart K, Visser J. L-arabinose and D-xylose catabolism in Aspergillus niger. J Gen Microbiol. 1989:135:2163-71.

46. Benocci T, Aguilar-Pontes MV, Zhou M, Seiboth B, de Vries RP. Regulators of plant biomass degradation in ascomycetous fungi. Biotechnol Biofuels. 2017;10:152.

47. Benocci T, Aguilar-Pontes MV, Kun RS, Seiboth B, de Vries RP, Daly P. ARA1 regulates not only L-arabinose but also D-galactose catabolism in Trichoderma reesei. FEBS Lett. 2018;592(1):60-70.

48. Battaglia E, Klaubauf S, Vallet J, Ribot C, Lebrun M-H, de Vries RP. XIr1 is involved in the transcriptional control of the pentose catabolic pathway, but not hemi-cellulolytic enzymes in Magnaporthe oryzae. Fungal Genet Biol. 2013;57:76-84.

49. Kowalczyk JE, Gruben BS, Battaglia E, Wiebenga A, Majoor E, de Vries RP. Genetic interaction of Aspergillus nidulans galR, $x \ln R$ and araR in regulating D-galactose and L-arabinose release and catabolism gene expression. PLoS ONE. 2015;10(11):e0143200.

50. vanKuyk PA, de Groot MJL, Ruijter GJG, de Vries RP, Visser J. The Aspergillus niger $\mathrm{D}$-xylulose kinase gene is co-expressed with genes encoding arabinan degrading enzymes and is essential for growth on arabinose and xylose. Eur J Biochem. 2001;268:5414-23.

51. Frommhagen M, Sforza S, Westphal AH, Visser J, Hinz SW, Koetsier MJ, et al. Discovery of the combined oxidative cleavage of plant xylan and cellulose by a new fungal polysaccharide monooxygenase. Biotechnol Biofuels. 2015:8:101.
52. Sun J, Tian C, Diamond S, Glass NL. Deciphering transcriptional regulatory mechanisms associated with hemicellulose degradation in Neurospora crassa. Eukaryot Cell. 2012;11(4):482-93.

53. Wang J, Gong Y, Zhao S, Liu G. A new regulator of cellulase and xylanase in the thermophilic fungus Myceliophthora thermophila strain ATCC 42464. 3 Biotech. 2018;8(3):160.

54. Battaglia E, Visser L, Nijssen A, van Veluw J, Wösten HAB, de Vries RP. Analysis of regulation of pentose utilisation in Aspergillus niger reveals evolutionary adaptations in the Eurotiales. Stud Mycol. 2011;69:31-8.

55. Jiang $Y$, Duarte $A V$, van den Brink J, Wiebenga A, Zou G, Wang C, et al. Enhancing saccharification of wheat straw by mixing enzymes from genetically-modified Trichoderma reesei and Aspergillus niger. Biotechnol Lett. 2016;38(1):65-70.

56. Benoit I, Culleton H, Zhou M, DiFalco M, Aguilar-Osorio G, Battaglia E, et al. Closely related fungi employ diverse enzymatic strategies to degrade plant biomass. Biotechnol Biofuels. 2015;8:107.

57. Langmead B, Trapnell C, Pop M, Salzberg SL. Ultrafast and memoryefficient alignment of short DNA sequences to the human genome. Genome Biol. 2009;10(3):R25.

58. Li H, Durbin R. Fast and accurate short read alignment with BurrowsWheeler transform. Bioinformatics. 2009;25(14):1754-60.

59. Li B, Dewey CN. RSEM: accurate transcript quantification from RNA-Seq data with or without a reference genome. BMC Bioinform. 2011;12:323.

60. Kayala MA, Baldi P. Cyber-T web server: differential analysis of highthroughput data. Nucleic Acids Res. 2012;40(Web Server issue):W553-9.

61. Grigoriev IV, Nikitin R, Haridas S, Kuo A, Ohm R, Otillar R, et al. MycoCosm portal: gearing up for 1000 fungal genomes. Nucleic Acids Res. 2014;42(Database issue):D699-704.

62. Cerqueira GC, Arnaud MB, Inglis DO, Skrzypek MS, Binkley G, Simison $\mathrm{M}$, et al. The Aspergillus Genome Database: multispecies curation and incorporation of RNA-Seq data to improve structural gene annotations. Nucleic Acids Res. 2014;42(Database issue):D705-10.

63. Altenhoff AM, Dessimoz C. Phylogenetic and functional assessment of orthologs inference projects and methods. PLoS Comput Biol. 2009:5(1):e1000262.

64. Overbeek R, Fonstein M, D'Souza M, Pusch GD, Maltsev N. The use of gene clusters to infer functional coupling. Proc Natl Acad Sci USA. 1999;96(6):2896-901.

65. Edgar R, Domrachev M, Lash AE. Gene Expression Omnibus: NCBI gene expression and hybridization array data repository. Nucleic Acids Res. 2002;30(1):207-10.

\section{Publisher's Note}

Springer Nature remains neutral with regard to jurisdictional claims in published maps and institutional affiliations.
Ready to submit your research? Choose BMC and benefit from:

- fast, convenient online submission

- thorough peer review by experienced researchers in your field

- rapid publication on acceptance

- support for research data, including large and complex data types

- gold Open Access which fosters wider collaboration and increased citations

- maximum visibility for your research: over $100 \mathrm{M}$ website views per year

At BMC, research is always in progress.

Learn more biomedcentral.com/submissions 